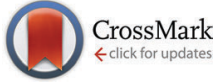

Cite this: New J. Chem., 2016, 40,5782

Received (in Montpellier, France) 17th November 2015 , Accepted 1st February 2016

DOI: $10.1039 / c 5 n j 03251 b$

www.rsc.org/njc

\title{
Influence of steric hindrance on the molecular packing and the anchoring of quinonoid $z$ witterions on gold surfaces $\dagger$
}

\author{
Minghui Yuan, ${ }^{a}$ Iori Tanabe, ${ }^{b}$ Jean-Marie Bernard-Schaaf, ${ }^{a}$ Qin-Yin Shi, ${ }^{c}$ \\ Vicki Schlegel, ${ }^{c}$ Rachel Schurhammer, ${ }^{d}$ Peter A. Dowben, ${ }^{\text {b }}$ Bernard Doudin, ${ }^{e}$ \\ Lucie Routaboul*a and Pierre Braunstein ${ }^{* a}$
}

\begin{abstract}
Driven by the huge potential of engineering the molecular band offset with highly dipolar molecules for improving charge injection into organic electrics, the anchoring of various $\mathrm{N}$-alkyl substituted quinonoid zwitterions of formula $\mathrm{C}_{6} \mathrm{H}_{2}(\ldots \mathrm{NHR})_{2}(\ldots \mathrm{O})_{2}\left(\mathrm{R}=\mathrm{iPr}, \mathrm{Cy}, \mathrm{CH}_{2} \mathrm{CH}(\mathrm{Et}) \mathrm{CH}_{2} \mathrm{CH}_{2} \mathrm{CH}_{2} \mathrm{CH}_{3}, \ldots\right)$ on gold surfaces is studied. The $\mathrm{N}-\mathrm{Au}$ interactions result in an orthogonal arrangement of the zwitterions cores with respect to the surface, and stabilize adsorbed compact rows of molecules. IR spectroscopy is used as a straightforward diagnostic tool to validate the presence of ultra-thin molecular films. When combined with computational studies, IR measurements indicate that the presence of a $\mathrm{CH}_{2}$ group in $\alpha$ position to the nitrogen atom is important for a successful anchoring through $\mathrm{N}-\mathrm{Au}$ interactions. The presence of such a flexible $\mathrm{CH}_{2}$ spacer, or of aryl groups, enables $\pi$-interactions with the surface, making possible the anchoring of enantiopure or sterically-hindered zwitterions. X-ray diffraction analyses indicate that the intermolecular spacing within a row of molecules can be modulated by the nature of the alkyl substituent R. This modulation is directly relevant to the electronic properties of the corresponding molecular films since these zwitterions are expected to form rows on gold surfaces similar to those observed in the bulk crystalline state.
\end{abstract}

\section{Introduction}

The stabilization of molecular films on surfaces, the formation of Self-Assembled Monolayers (SAMs) on metal surfaces, and the study of their properties continue to garner considerable interest (more than 1500 articles and patents from 2000 to 2015). This includes studies on the nature of the anchoring groups, the substrate/molecule or molecules/molecules interactions,

\footnotetext{
${ }^{a}$ Laboratoire de Chimie de Coordination, Institut de Chimie (UMR 7177 CNRS), Université de Strasbourg, 4 rue Blaise Pascal, 67081 Strasbourg, France. E-mail: lroutaboul@unistra.fr, braunstein@unistra.fr

${ }^{b}$ Department of Physics and Astronomy, Nebraska Center for Materials and Nanoscience, University of Nebraska-Lincoln, Lincoln, NE 68588, USA. E-mail: pdowben@unl.edu

${ }^{c}$ Department of Food Science and Technology, University of Nebraska - Lincoln, 326 Food Industry Complex, Lincoln, NE 68583-0919, USA

${ }^{d}$ Laboratoire de Chimie moléculaire de l'état solide (UMR 7140 CNRS), Université de Strasbourg, 1 rue Blaise Pascal, 67081 Strasbourg, France ${ }^{e}$ Institut de Physique et Chimie des Matériaux de Strasbourg (UMR 7504 CNRS), Université de Strasbourg, 23 rue du Loess B.P. 43, 67034 Strasbourg, France. E-mail: bdoudin@unistra.fr

$\dagger$ Electronic supplementary information (ESI) available. CCDC 1437115-1437117. For ESI and crystallographic data in CIF or other electronic format see DOI: 10.1039/c5nj03251b
}

the orientation of the molecules after deposition, ${ }^{1}$ as well as their subsequent modification on the surface for example by complexation of anchored molecules to metal ions. ${ }^{2}$ Potential applications motivate improvements of the characterization methods of SAMs, and/or the development of new systems with unique features. ${ }^{3}$ Generally, high quality SAMs are needed to obtain the required properties necessary for applications for e.g. the protection of materials, ${ }^{4}$ medical applications (prosthesis) ${ }^{5}$ the fabrication of functionalized electrodes for molecular recognition and sensing devices or for nanoelectronics. ${ }^{6}$ In the latter case, an important objective is to use SAMs to improve the interface between metals and organic layers for better charge injection and extraction. ${ }^{7}$ For such purpose, dipolar molecules have great potential for a chemical-based engineering of the molecular band offset at the interface. ${ }^{8}$

We recently described the formation of SAMs made of quinonoid zwitterions deposited on conductive substrates. ${ }^{9}$ These potentially anti-aromatic molecules (Scheme 1$)^{10}$ contain two $6 \pi$ electrons subsystems delocalized over five atoms. The anionic system (trimethyne oxonol) is chemically connected to the cationic moiety (trimethyne cyanine) through two carbon-carbon single bonds, which electronically isolate the two sub-systems, leading to a strong molecular dipole moment of 10 debyes. 


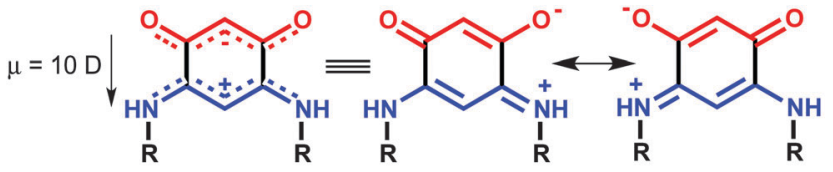

$\mathrm{R}=\mathrm{H}$ (1), $n$ - $\mathrm{Bu}$ (2), $\mathrm{CH}_{2} \mathrm{CH}_{2} \mathrm{CH}_{2} \mathrm{SMe}$ (3), $\mathrm{CH}_{2} \mathrm{CH}_{2} \mathrm{CH}_{2} \mathrm{OMe} \mathrm{(4),} \mathrm{CH}_{2} \mathrm{Ph}$ (5)

Scheme 1 Resonance forms of the quinonoid zwitterions previously investigated. ${ }^{9}$

With their large intrinsic dipoles, these molecules represent excellent candidates for fundamental investigations into the complex interplay between dipole interactions and surface chemistry at the dipole/substrate interface. ${ }^{9 a}$ We previously showed that gold substrates can be fully covered by thin and homogeneous molecular films of well-organized dipoles. ${ }^{9 a, b, d}$ These films provide an efficient way to screen the interface dipole, always present between metallic electrodes and organic films. ${ }^{11}$ Moreover, a comparative study carried out on five different zwitterionic molecules showed that changing the nature of the $\mathrm{R}$ substituent attached to the nitrogen atoms opens a way for chemically-driven modifications of the electronic properties of the molecular adlayers. ${ }^{9 d}$

Another advantage of these quinonoid zwitterions resides in the diversity of possible substituents, which provides opportunities for modifying the structure of the adsorbate. Our long-term goal is to identify/design the adequate substituent for tuning the desired electronic property of the metal-adsorbate, i.e. displacing appropriately the work function of the electrodes while tuning the adlayer charge transfer transparency. We have shown previously that zwitterions $\mathbf{2}$ and $\mathbf{5}$ anchor on the gold surface with a preferential orientation of the "quinonoid cores" perpendicular to the gold surface (Scheme $2 \mathrm{a}-\mathrm{d}$ ), when the film is grown from solution (note however that the bonding situation is different when the zwitterion film is grown from the vapor phase). ${ }^{12}$ As shown in Scheme $2 \mathrm{a}-\mathrm{c}$, all dipole moments in the first zwitterion layer are oriented in the same direction. ${ }^{9 a, b, d}$ We found a thickness of typically $1 \mathrm{~nm}$ for the thinnest films, which suggested the presence of a second layer of molecules, not shown here and in the following schemes, where we only represent the first interface layer for clarity reasons. The energetics leading to the arrangement of the first layer result from several combined effects, e.g. the bonding of the $\mathrm{N}$ atom to the $\mathrm{Au}$ substrate, as identified by X-ray photoemission (XPS), the electrostatic interactions which drive the intrinsic molecular dipoles, deposited from solution, to align with the interface dipole moment of the metallic substrate. The arrangement of the molecules on the gold surface was discussed as a succession of molecular 'rows' (Scheme 2a-c). The $\pi-\pi$ interactions governing the molecular packing, in combination with other intermolecular interactions (e.g. hydrogen bonding), result in major changes in the intermolecular charge delocalization, more akin to a semimetalliclike behavior of the ultra-thin film prepared from $5 .{ }^{9 c}$ By varying the spacing between molecules of the same row, one might observe changes of the electronic properties of the metal-SAMs system. Our goal here is to investigate by single crystal X-ray diffraction the structural consequences on the molecular packing of a change in the steric properties of different $N$-substituents and its impact on the anchoring of the molecules on a gold surface. Such studies should help identify the structural features favoring the formation of molecular-thin adlayers.

Considering that some of these zwitterions can be anchored to the gold surface through N-Au interaction (Scheme $2 \mathrm{c}$ and d), ${ }^{9 a, b, d}$ we focus here on selected aspects of the steric influence of the $\mathrm{N}$-alkyl substituent. Indeed, the use of $\mathrm{N}$-alkyl quinonoid zwitterions offers several advantages: (i) the variation of only one chemical parameter permits a better comparison between molecules for a given type of anchoring mode; (ii) a large diversity of such molecules is accessible from commercially available reagents; (iii) no particular experimental conditions are required (inert atmosphere...); (iv) their high stability, a)
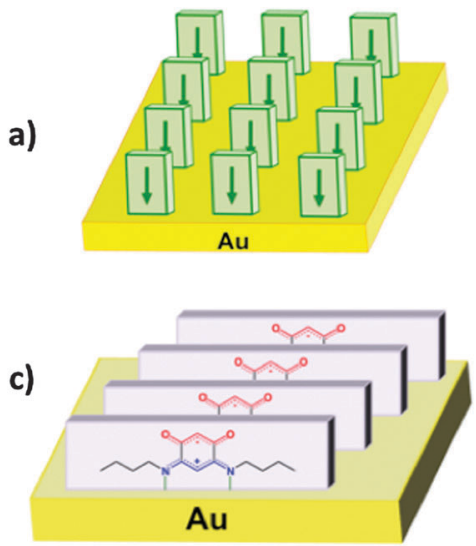

b)

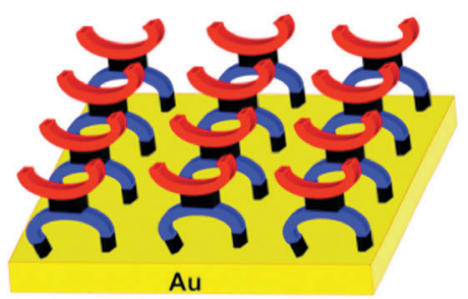

d)

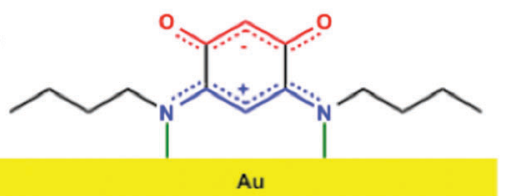

Scheme 2 Molecular arrangement in the first layer of the film on the gold surface. (a and b) Observed for quinonoid zwitterions 2 and $\mathbf{5}$. Sketches represent three molecular rows on the gold substrate. In (a), parallelepipeds represent the quinonoid core and the arrows indicate the dipoles directions of the free molecules. In (b), the anionic and cationic parts of quinonoid zwitterions are represented in red and blue, respectively. (c) Molecular row of zwitterions $\mathbf{2}$ in the film formed on the gold substrate. (d) Sketch of the proposed bonding mode of the $\mathrm{N}$-butyl zwitterion on gold (sketch a is reproduced from ref. $9 a$ with permission from the PCCP Owner Societies. Sketches c and d are reprinted with permission from ref. $9 d$. Copyright 2012 American Chemical Society). 
with observed shelf life-times exceeding months in the solid state. Varying the number of carbon atoms of the $N$-alkyl substituent (e.g. from butyl to octyl) is expected to have negligible effects on the spacing between molecules which pack in the same row. In order to modulate this intermolecular spacing, we also investigate quinonoid zwitterions having branched or cyclic alkyl substituents. However, a too large steric hindrance at the $\mathrm{N}$-substituent could hamper the $\mathrm{N}-\mathrm{Au}$ interaction and prevent molecular anchoring on the surface.

Taking advantage of our extensive experimental characterization of thin films of $\mathbf{1}, \mathbf{2}, \mathbf{4}$ and $\mathbf{5}$ obtained by self-assembly on $\mathrm{Au}^{9}{ }^{9}$ we wish to address the following questions: can we extend this family of molecules for various and better surface anchoring? Can a simple pass/fail test be applied to determine the anchoring of the quinonoid zwitterions on a metallic substrate, and deduce simple rules based on the packing of these molecules in the crystalline state? Such studies represent the first step towards electronic properties investigations, using molecular design to determine the best candidates for applications. A key issue is whether the steric properties of the $N$-substituent of the zwitterions could possibly hamper the establishment of N-Au interactions and prevent molecular anchoring on the surface. We also expand the library of candidate molecules with the specific objective to form films of enantiopure, strong dipolar molecules on substrates.

\section{Results and discussion}

\section{Chemical structure of selected zwitterions}

The new molecules investigated in this work, complementing those studied in ref. $9 a, b$ and $d$ and by others, ${ }^{13}$ are shown in Table 1, which also summarizes the optimum conditions used for their synthesis. Here we establish that microwave activation greatly facilitates the synthesis of new target quinonoid zwitterions.

In previous work, we took advantage of a combination of several characterization methods (photoemission, IR, XPS) to assess the anchoring of the $N$-butyl zwitterion 2 through the nitrogen functions (Scheme 2, ref. $9 a$ and $d$ ) and provide insight into the orientation of the molecular backbone. A bulky $\mathrm{N}$-substituent is expected to be detrimental, or even prevent the anchoring and stabilization of a molecular film on gold. Two important geometrical parameters need to be considered: the distance between the bulky moiety in $\mathrm{R}$ and the $\mathrm{N}$ atom (in $\alpha$, $\beta$ or $\gamma$ position to nitrogen), and the resulting steric hindrance. The molecules presented in Table 1 were selected to evaluate the impact of these two parameters. Zwitterions $\mathbf{6}$ and $\mathbf{7}$ have at least one methylene group in $\alpha$ position to nitrogen. Since the variation of the steric hindrance occurs in $\beta$ position, we anticipate that significant differences may only be observed with a very bulky R group. For the zwitterions 8-13, steric hindrance occurs closer to the nitrogen atom (in $\alpha$ position) and increases progressively from 8 to 10. The cyclohexyl $N$-substituent in $\mathbf{9}$ is less flexible and more constrained than the $N$-substituent in $\mathbf{8}$. The presence of an aromatic substituent in 11-13 could increase the surface anchoring ability of the molecule or allow a new anchoring mode,
Table 1 Synthesis of zwitterions with a bulky $N$-substituent

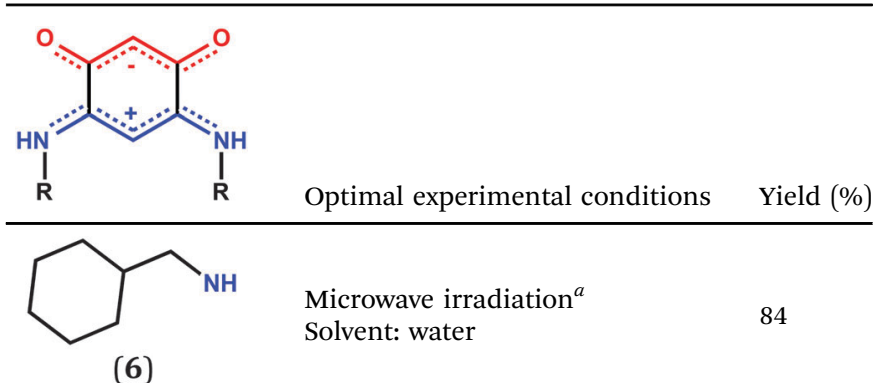

(7)

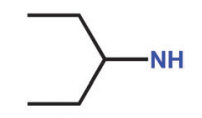

(8)

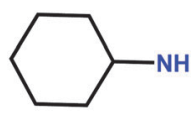

(9)<smiles>CC(=N)C1CCCCC1</smiles>

(10)<smiles>NC1CCCc2ccccc21</smiles>

(11)<smiles>N[C@H]1CCc2ccccc21</smiles>

(12)<smiles>NC1Cc2ccccc2C1</smiles>

(13)
Microwave irradiation $^{a}$ Solvent: water

Microwave irradiation $^{a}$ Solvent: water

Microwave irradiation $^{a}$ Solvent: water

Thermal conditions (oil bath) ${ }^{b}$ Solvent: water

60

Microwave irradiation ${ }^{a}$ Solvent: water

Microwave irradiation $^{a}$ Solvent: water

28

Microwave irradiation $^{a}$ Solvent: water 87

${ }^{a}$ The reactions were performed in a closed system (sealed $\mathrm{CEM}^{\circledR} 10 \mathrm{~mL}$ reactor), $2.5 \mathrm{~mL}$ of water, power up to $80 \mathrm{~W}, 2 \mathrm{~min}$ at $100{ }^{\circ} \mathrm{C} .{ }^{b}$ Preheated oil bath, $10 \mathrm{~mL}$ of solvent.

as previously reported. ${ }^{14}$ The relative position of the phenyl substituent with respect to the nitrogen function could influence the orientation of the quinonoid core after anchoring on the substrate. Note that zwitterions $\mathbf{7}$ and 10-12 are chiral molecules and zwitterions $\mathbf{1 0}$ and $\mathbf{1 1}$ are enantiopure.

\section{Synthesis of new zwitterions}

The family of quinonoid zwitterions investigated can be typically prepared by two different methods (Scheme 3).

Following method A, the target molecule directly results from the reaction of an excess primary amine with diaminoresorcinol 

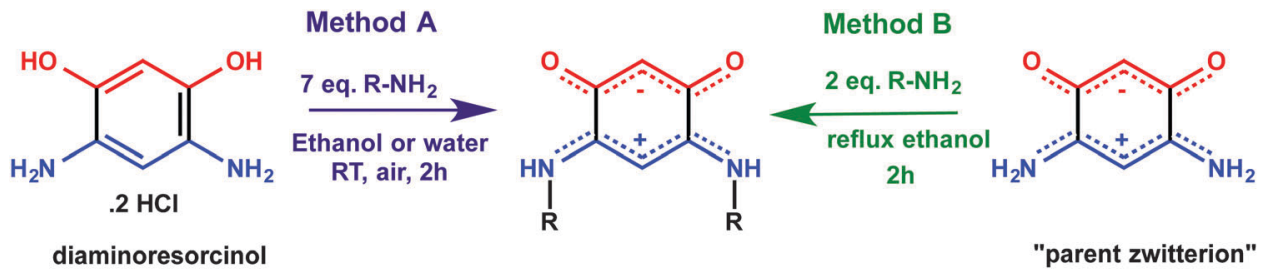

"parent zwitterion"

1

Scheme 3 General scheme of the two synthetic methods leading to quinonoid zwitterions.

(commercially available). Following method B, the desired compound is obtained by a trans-amination reaction from the readily available "parent zwitterion" $1 .{ }^{10}$ Method B requires the use of only two equivalents of primary amine, a significant economical advantage over method A, particularly for zwitterions 10-13. Moreover, a simple work-up leads to pure compounds. Sterically hindered $N$-substituents disfavor access to the new zwitterions presented in Table 1. An optimization of the yields and reaction times was performed, and a comparative study of these synthetic details is provided in the ESI. $\dagger$ Although method B has not been previously applied in water, because of the increased thermal decomposition of the "parent zwitterion" 1 in water as compared to ethanol, this pathway was the only procedure leading to the desired compounds. To further increase the reaction yield, a reduction in the rate of decomposition of the "parent zwitterion" 1 should be sought. One approach is to use an activating technique allowing the reaction to be performed at higher temperature for shorter reaction times. ${ }^{15}$ We thus considered microwave irradiation as an attractive possibility, even though very few transamination reactions performed under microwave irradiation have been described in the literature. ${ }^{16}$ Performing the trans-amination reaction under microwave irradiation, in water, afforded better yields (Table 1 and ESI $\dagger$ ), except for 10. The fact that zwitterions 8 and $\mathbf{1 2}$ were obtained in much lower yields is probably due to the solubility of $\mathbf{8}$ in water (product loss during work-up), and in the case of 12, to the lower miscibility of the corresponding amine with water, resulting in a biphasic mixture. These results show that microwave activation can bring about significant improvements and offers a fast (typical 2 min reaction time) and efficient access to several sterically-hindered or chiral zwitterions.

\section{Structural analyses by X-ray diffraction}

Single crystals of zwitterions 9-11 were obtained at room temperature by slow diffusion of pentane into their dichloromethane solution. Their molecular structures (Fig. 1) were elucidated by X-ray diffraction. Crystallographic details are given in the ESI $\dagger$ (Table S1).

A detailed comparative study of the X-ray structures of zwitterions 9-11 is provided in the ESI. $\dagger$ Not surprisingly, the absence of $\mathrm{a} \mathrm{CH}_{2}$ group in $\alpha$ position to the nitrogen atom considerably influences the molecular arrangement in the solid state (ESI $\left.{ }^{\dagger}\right)$. A head-to-tail arrangement of the molecules and the formation of molecular rows in the direction orthogonal to the quinonoid core are usually observed in the solid state structures of quinonoid zwitterions.

\section{Head-to-tail arrangement}

Molecules with bulky substituents are generally arranged in a head-to-tail manner (Fig. 2). In this case, the angle formed by the "quinonoid core" $\left(\mathrm{C}_{6} \mathrm{O}_{2} \mathrm{~N}_{2}\right)$ of two adjacent molecules is around $120-150^{\circ}$ whereas adjacent molecules of 3 are coplanar (Fig. 2).

\section{Molecular rows in the orthogonal direction to the quinonoid core}

Compound 10 co-crystallizes with water molecules that interact via $\mathrm{H}$-bonds with the zwitterions and thereby modify the molecular arrangement. In the structure of $\mathbf{9}$, no molecular rows are formed, which is unusual. In contrast to $\mathbf{9}$, bonding interactions between the tetrahydronaphthyl substituent of $\mathbf{1 1}$ and the trimethyne oxonol part of neighboring molecules lead to an arrangement in which a molecular row is perpendicular to the C6 core (Fig. 3).

Interestingly, the X-ray diffraction analysis establishes that the molecular arrangement of $\mathbf{1 1}$ is closer to that found for the isopropyl zwitterion 14 (its X-ray structure has been briefly described previously ${ }^{17}$ and is detailed in the ESI $\dagger$ ) than for 9. Predicting the molecular arrangement in the solid state is very difficult, if not impossible, in view of the complex interplay of interactions at work.
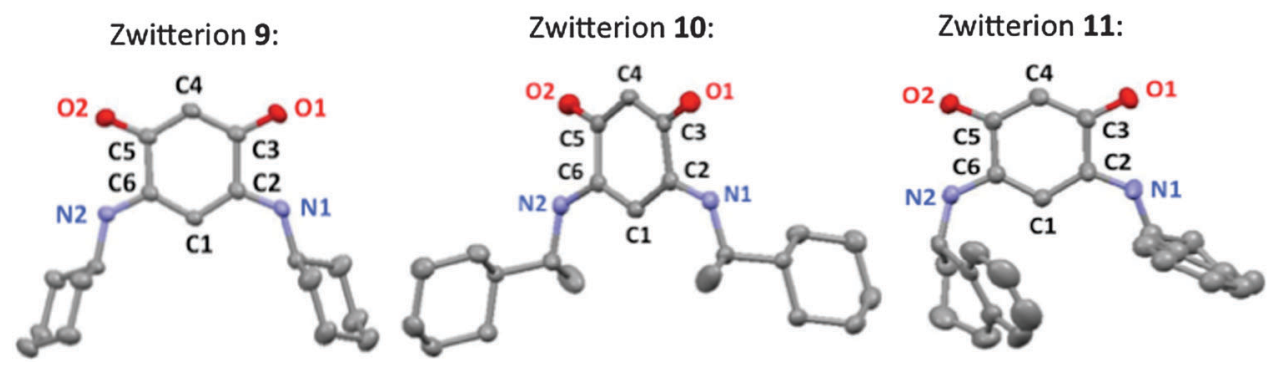

Fig. 1 Mercury views of the quinonoid zwitterions 9-11. Thermal ellipsoids are drawn at the 50\% probability level. $\mathrm{H}$ atoms are not shown for clarity. 
Zwitterion 3:

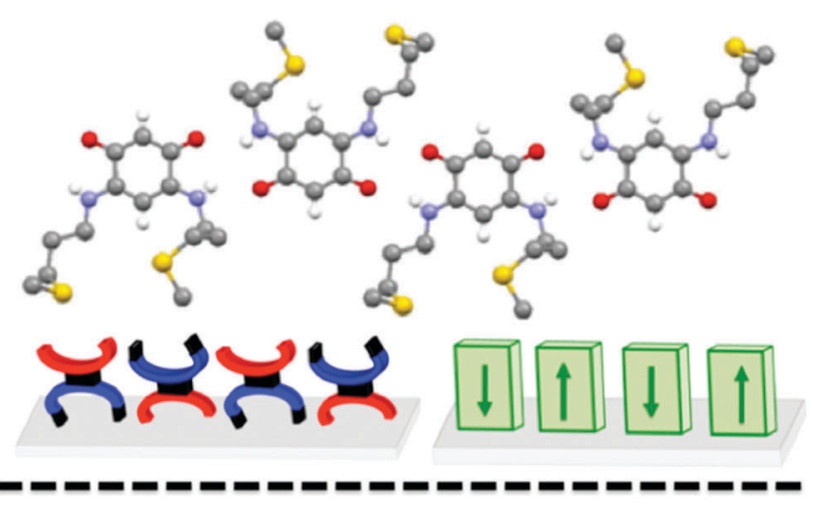

Zwitterion 11:

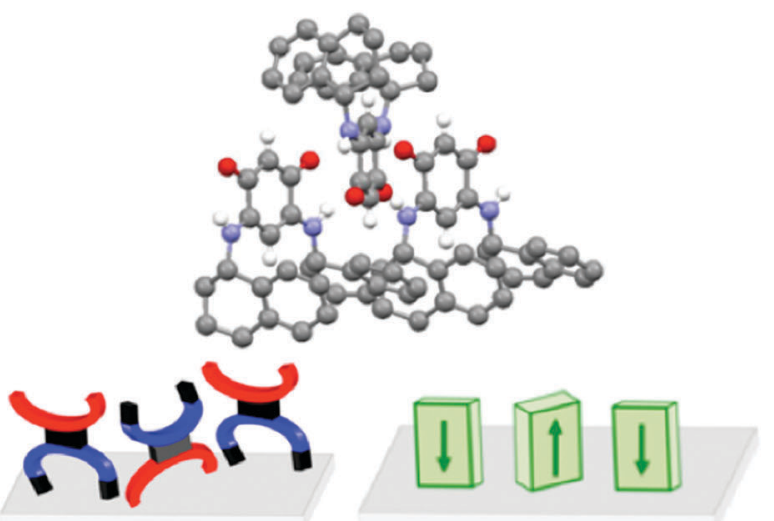

Fig. 2 Head-to-tail arrangement of zwitterions $\mathbf{3}$ and $\mathbf{1 1}$ in the crystalline state. In the sketch on the molecular arrangement of $\mathbf{3}$ and 11, parallelepipeds represent the quinonoid zwitterion core and the arrows indicate the direction of the dipoles. Anionic and cationic parts of quinonoid zwitterions are respectively represented in red and blue, respectively.

A better quantitative insight into the molecular row packing is provided in Fig. 4 and 5 , where opportunities for $\pi-\pi$ stacking are shown to exist between sufficiently close packed molecules. More specifically, we wish to highlight the key importance of (i) the spacing between two planes containing the quinonoid cores (Fig. 4 and Fig. S1, ESI $\dagger$ ), (ii) the interatomic distances (Fig. 5a, b and Fig. S2a, ESI $\dagger$ ), and (iii) the spacing between the
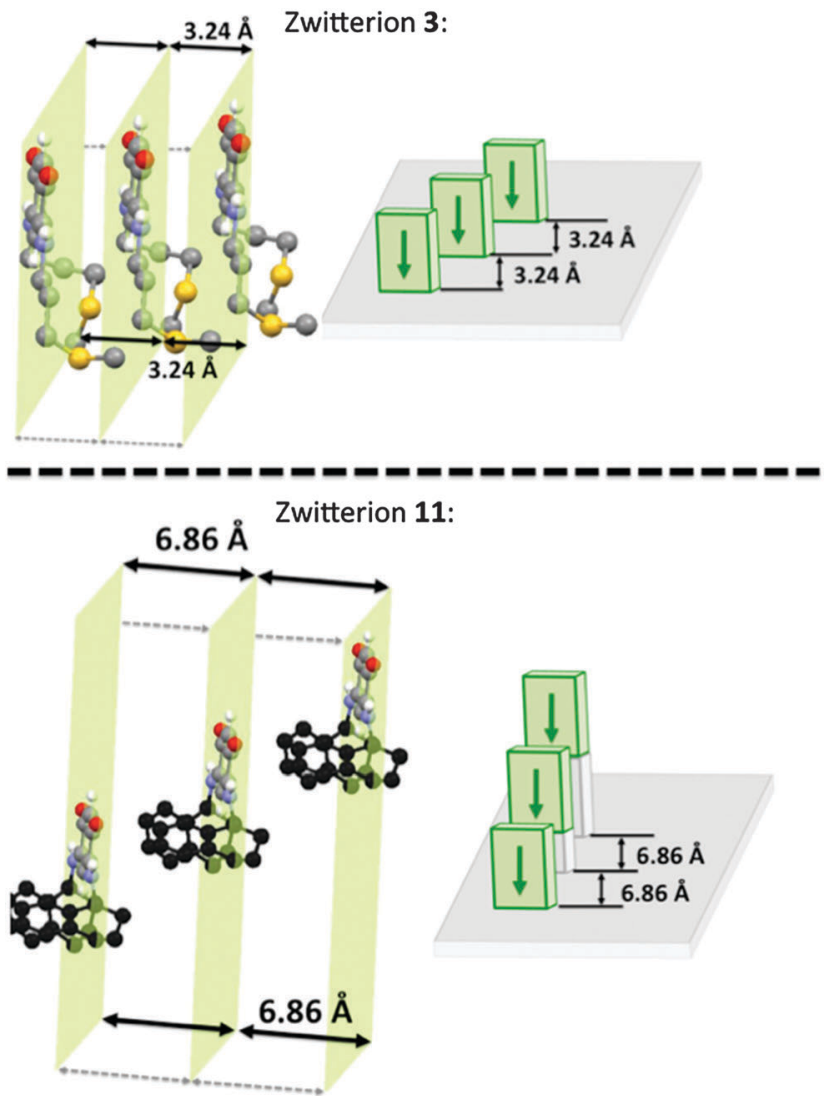

Fig. 4 Packing of molecules 3 and $\mathbf{1 1}$. The spacing between the mean planes containing the quinonoid core of $\mathbf{3}$ is $3.24 \AA$ whereas the separation observed for 11 is $6.86 \AA$. Views showing rows of parallel molecules, parallelepipeds represent the quinonoid core and the arrows indicate the direction of the dipole.

anionic part and the cationic part of neighboring molecules (Fig. 5c and d and Fig. S2b, ESI $\dagger$ ). The distances observed for the zwitterion 11 are compared with those of 3, 5 and 14 in Table 2.

In the packing of molecules 3, 5, 11 and 14, the planes of the molecular cores are parallel to each other. Likely due to repulsion effects, the molecules are offset with respect to the
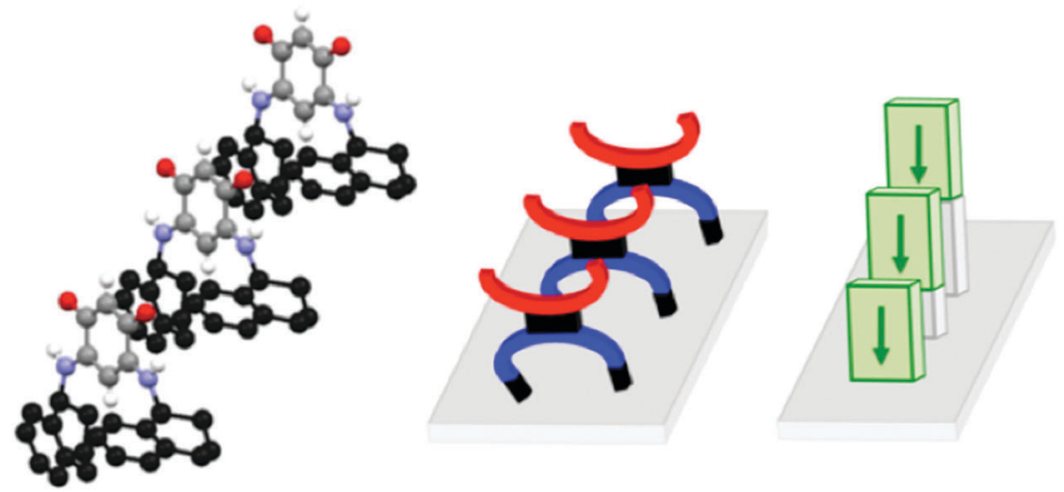

Fig. 3 A row of molecules 11. Parallelepipeds represent the quinonoid zwitterion core and the arrows indicate the direction of the dipoles. The anionic and cationic parts of the quinonoid zwitterions are represented in red and blue, respectively. 
a)

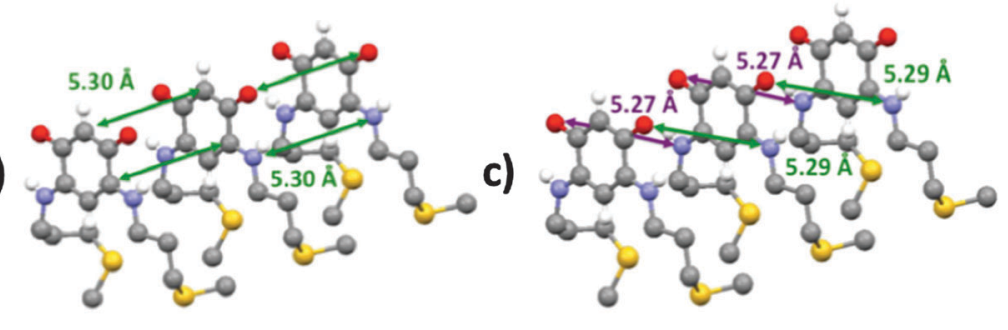

b)

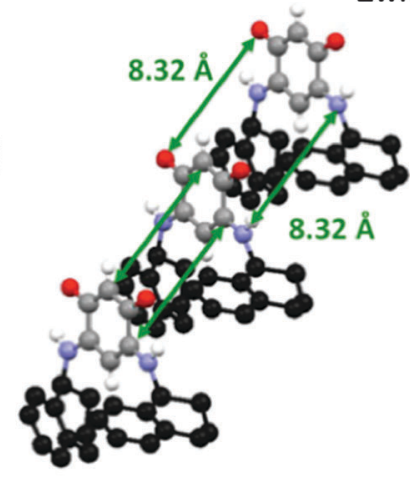

Zwitterion 11:

\section{Zwitterion 3:}
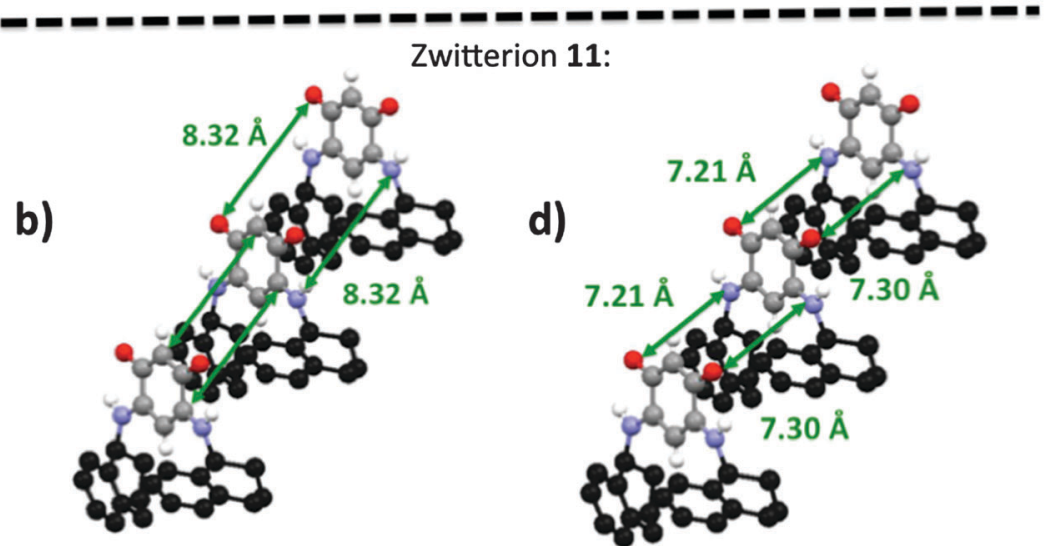

Fig. 5 ( $a$ and $b$ ) Interatomic spacing between corresponding atoms between two neighboring molecules. (c and d) Spacing between the anionic and the cationic moieties of neighboring molecules.

packing direction. In the case of 3 , they are shifted horizontally whereas they are shifted upward in $\mathbf{1 1}$ (Fig. 4).

The molecular packing of zwitterions 5 and $\mathbf{1 4}$ (Fig. S1, ESI $\dagger$ ) is similar to that of 11. It appears that the lack of methylene group in $\alpha$ position to the nitrogen atom results in a slight increase of the spacing between two adjacent planes. As illustrated by zwitterion 11, an increase of the steric hindrance of the substituent results in an increase of both the interplane spacing and the interatomic distances between two parallel molecules (Table 2).

Interestingly, the distance between the anionic and the cationic moieties of neighboring molecules increases in the sequence from 5, 14, 3 to 11 (Table 2). We previously attributed to this interaction the semi-metallic character of the benzyl zwitterionic film on gold surface. ${ }^{9 c}$ This property will be favored by a short spacing between the two $\pi$-systems and this is the case when the molecules are upward shifted in the packing (Fig. 4). Moreover, the lack of methylene group in $\alpha$ position to the nitrogen atom appears to favor this type of packing.

Our structural investigations have shown that the arrangement along the molecular column is highly dependent on the $\mathrm{R}$ substituent.

\section{Succession of molecular rows}

Fig. 6 represents a succession of three molecular rows of zwitterions 3 and 11, their arrangement is highly sensitive to a modification of the head-to-tail arrangement imposed by the steric hindrance of the substituent.

This comparative study of the zwitterions and their X-ray structures allows us to validate our hypothesis that in the solid state and within a molecular row, the spacing between neighboring
Table 2 Different spacings ( $\AA$ ) observed in zwitterions 3, 5, 11, 14

Spacing
between the
2 systems $(\AA)$

(5)<smiles>CC(C)N</smiles>

6.86

8.32

7.21

7.30

(14)

3.97

5.70

4.45

4.58

molecules depends on the $N$-substituent. This study also illustrates the difficulties encountered to predict the molecular arrangement of a compound in the absence of X-ray diffraction data.

\section{Studies of the anchoring of the zwitterions on gold}

In order to study the anchoring of molecules on a gold surface, we need a readily available method to determine whether they 


I

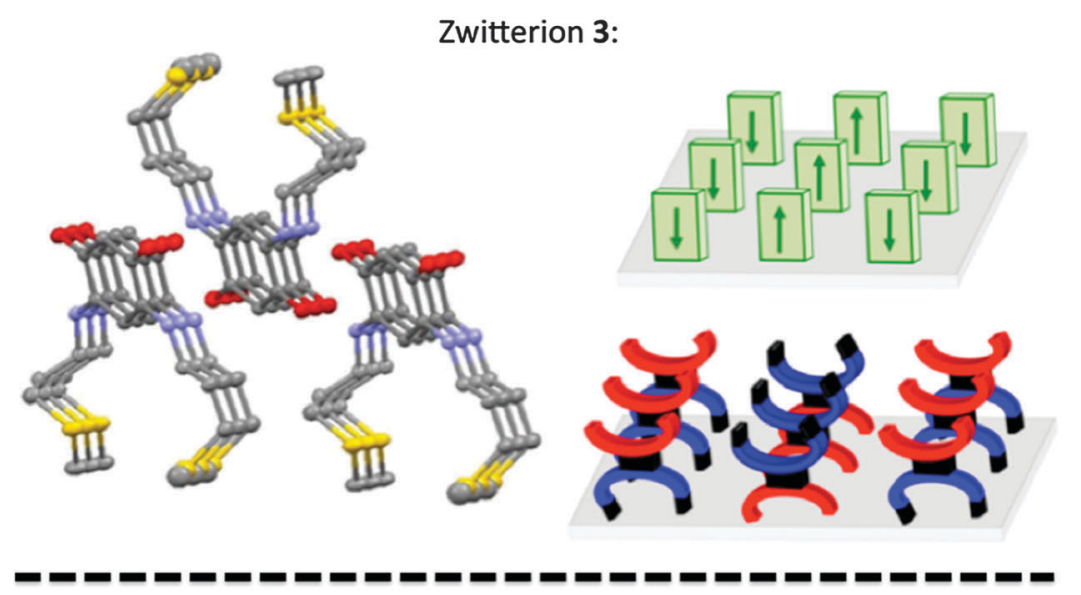

Zwitterion 11:

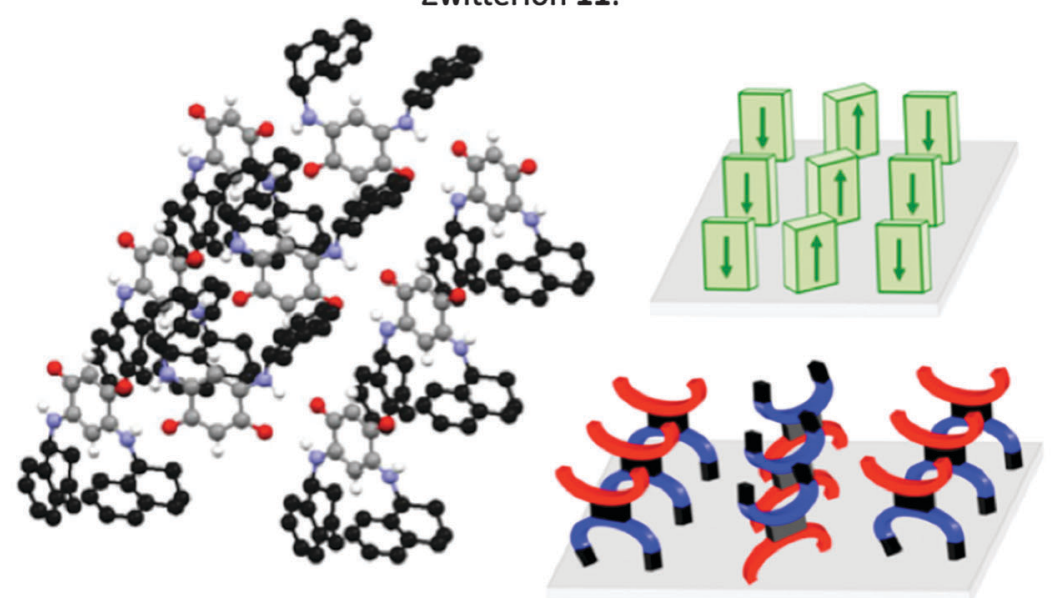

Fig. 6 Succession of 3 molecular rows of zwitterions 3 and 11 in the crystalline state. In the sketch on the molecular arrangement of 3 and $\mathbf{1 1}$, parallelepipeds represent the quinonoid zwitterion core and the arrows indicate the direction of the dipoles. The anionic and cationic parts of the quinonoid zwitterions are represented in red and blue, respectively.

are still present on the substrate after rinsing. Although the combination of photoemission and inverse photoemission spectroscopies together with XPS provides strong evidence for the anchoring of the molecules, these techniques are time-consuming and may induce molecular degradation. In contrast, infrared spectroscopy is a noninvasive technique that allows for a much faster assessment of the integrity of the molecules after adsorption and can establish the anchoring mode and the preferential orientation of the molecules on the surface. ${ }^{18}$ IR spectroscopy is sensitive enough to reach submonolayer adsorption sensitivity ${ }^{18 d}$ and is commonly used to characterize molecular adsorption on a metal substrate. ${ }^{18}$ It can also provide insight into molecule-molecule and moleculesubstrate interactions, information on the structure of the molecular film ${ }^{18 a, c}$ and may differentiate conformers. ${ }^{18 d, f}$ The typical IR absorption fingerprints of these quinonoid zwitterions will allow us to gain some insight into the anchoring orientation and the preferential anchoring when the surface is patterned. ${ }^{9 a, d}$

Fig. 7 presents the IR spectra obtained for compound 7, with a comparison between the bulk data and the molecular film deposited on a gold surface.

The IR spectrum for the zwitterion on gold is mode-softened with respect to the data taken in the bulk. This is both expected and understandable: the molecules are tied to the surface, with intermolecular interactions screening the dipoles and making the harmonic oscillator mass effectively "heavier". There is nevertheless a good correspondence between the three spectra, and we can conclude that zwitterion 7 is well anchored on the gold surface, showing unambiguously characteristic backbone vibration modes.

In contrast, the IR spectrum of zwitterion 8 on gold (Fig. 8) reveals that almost no or only few molecules are anchored on the substrate. IR spectroscopy thus provides a straightforward assessment of the efficiency of the anchoring procedure, the spectrum being dominated by a heterogeneous mixture of symmetric and anti-symmetric $\delta$ (methyl) and $\nu(\mathrm{C}-\mathrm{C})$ modes and few of the characteristic vibrational modes associated with the zwitterion backbone (Fig. 7 and 8). This suggests that if adsorption does occur, it is not dominated by intact quinonoid zwitterion species with the intrinsic dipole aligned along the surface normal.

For comparison, the IR spectra of molecules 6-13 on gold surfaces are shown in Fig. 9 (see also Fig. S4-S10, ESI $\dagger$ ). Whereas only few or no molecules of zwitterions $6,8,9$ and $\mathbf{1 0}$ were detected, the IR signature of zwitterions $\mathbf{7}$ and $\mathbf{1 1}$ on the surface 


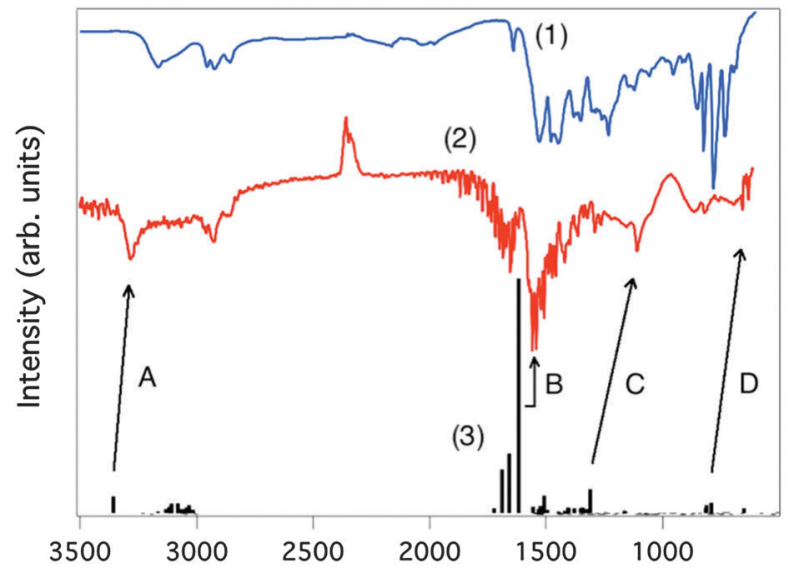

Wave number $\left(\mathrm{cm}^{-1}\right)$

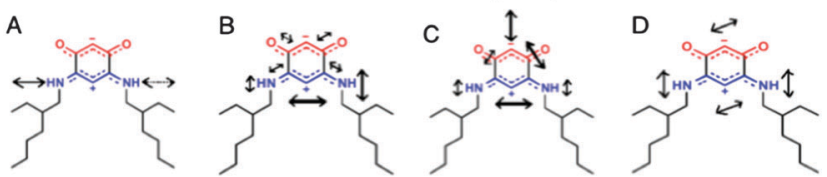

Fig. 7 The data in blue (1) correspond to the IR spectrum of zwitterion $\mathbf{7}$ in the solid state and in red (2) the IR spectrum of the gold surface functionalized by 7 . In black is represented the calculated spectra (based on a standard density functional theory harmonic oscillator forces, using the B3LYP/6-31G** hybrid functional and basis set described in more details below) of the compound with the eigenvalues indicated (with no correction for anharmonicity nor substrate screening), and the intensities estimated (3) from density functional theory.

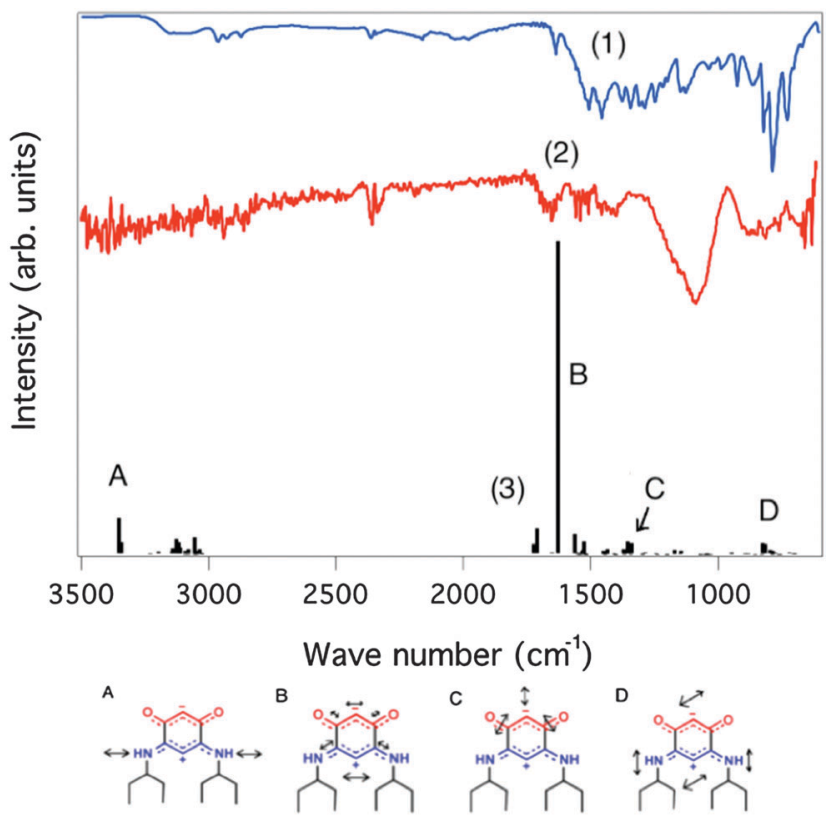

Fig. 8 The data in blue (1) correspond to the IR spectrum of the zwitterion in the solid state and in red (2) the IR spectrum of the gold surface functionalized by compound $\mathbf{8}$. The theoretical spectra are shown in black (3), with the eigenvalues and the estimated intensities.

is clearly observed; $\mathbf{1 2}$ and $\mathbf{1 3}$ also possibly bind. In the latter case, the IR spectra are less clear because of complications from out-of-plane contributions from the $\mathrm{C}-\mathrm{C}$ stretching modes in

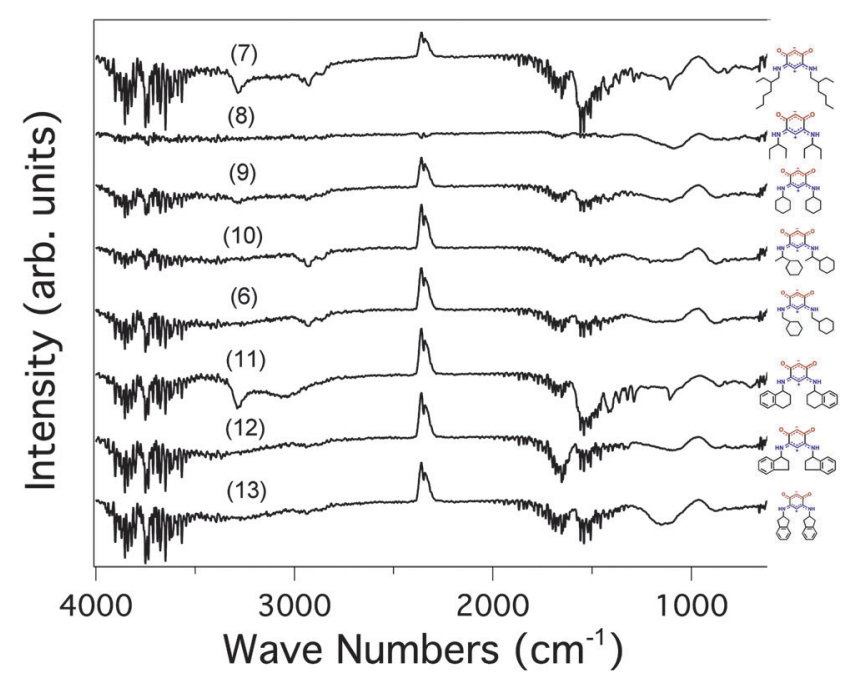

Fig. 9 Comparison of IR spectra of the gold surfaces functionalized by zwitterions 7-13.

the aromatic substituents. For molecules 7 and 11-13 deposited from solution on gold, additional washing did not change the IR spectra of the functionalized surface. Results obtained for compounds 7 and $\mathbf{1 1}$ (possibly for $\mathbf{1 2}$ as well) thus indicate that anchoring of chiral zwitterions on a gold surface can be achieved. The evidence of diminished anchoring of $\mathbf{9}$ demonstrates that the presence of the cyclohexyl substituent in $\alpha$ position to nitrogen hampers the $\mathrm{N}-\mathrm{Au}$ interaction. We can reasonably conclude that the anchoring of the molecules 11-13 is favored by the presence of aryl substituents.

The drastic difference between the IR spectra of zwitterions 7 and 8 is intriguing. Can the lack of anchoring of zwitterion 8 be just explained by a too important steric hindrance of the substituent or does it indicate more generally that the presence of a methylene group in $\alpha$ position to the nitrogen atom is crucial for an efficient bonding through $\mathrm{N}-\mathrm{Au}$ interaction? In order to answer this question, a theoretical study of the effect of steric hindrance was performed.

\section{Further theoretical investigations}

In all the structures determined here by X-ray diffraction, the quinonoid zwitterions have the conformation $\mathbf{A}$ with the two $\mathrm{N}$-bound hydrogen atoms directed towards the anionic part of the molecule (Fig. 10). This conformation appears also to be the most stable in the gas phase (see Table 3). However, to allow anchoring through $\mathrm{N}-\mathrm{Au}$ interaction, the molecule should have conformation $\mathbf{B}$, obtained by rotation of $180^{\circ}$ about the $\mathrm{C} \ldots \mathrm{N}$ bonds (Fig. 10).

Steric hindrance and flexibility of the $N$-substituents are two important reasons that can hamper this rotation. They can be quantified by two parameters: (i) the energy difference between the two conformers and (ii) the energy barrier required to operate a rotation of $180^{\circ}$ about the $\mathrm{C} \ldots \mathrm{N}$ bond.

DFT calculations were performed to gain an insight into the vibrational mode energies (see Experimental section and Fig. S11 and S12, ESI $\dagger$ ). The energy of rotation around the $\mathrm{C} \cdot \mathrm{N}$ bond was determined by performing constrained optimization 

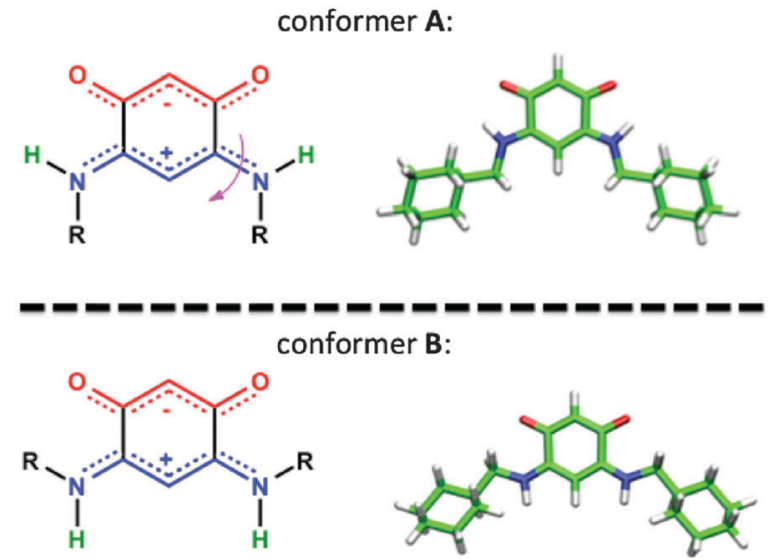

Fig. 10 Transformation of conformer $\mathbf{A}$ to conformer $\mathbf{B}$ (left). Typical structures of both conformers showing the $\mathrm{H}_{\mathrm{N}}$ position of each conformer (right).

of the geometries as a function of the dihedral angles for different zwitterions.

\section{Difference of energy levels between the 2 conformers}

The energy differences summarized in Table S2 (ESI $\dagger$ ) indicate that conformers B are less stable than their respective conformers A by $c a .70 \mathrm{~kJ} \mathrm{~mol}^{-1}$. The steric bulk of the substituent appears to have little or no influence on the difference of stability of the two conformers. The results obtained at the B3LYP/6-31+G** level of calculation indicate that this energy is maximal for a dihedral angle of about $120^{\circ}$. The results are almost the same at the $\mathrm{HF} / 6-31+\mathrm{G}^{* *}$ level for the same zwitterions and at the DFT and MP2 level of theory tested for the $N$-ethyl zwitterion 15. These results thus tend to indicate that the stability difference between the conformers is not the limiting parameter for the anchoring of the zwitterion on the surface.

\section{Energy of rotation around the $\mathrm{C} \cdots \mathrm{N}$ bond}

The rotational barrier around the $\mathrm{C} \ldots \mathrm{N}$ bond, i.e. the energy required to allow a $180^{\circ}$ rotation about the $\mathrm{C} \cdots \mathrm{N}$ bond, corresponds to the maximum of the curves plotted in Fig. S11 and S12 (ESI $\dagger$ ). This barrier is found to be quite high (more than $100 \mathrm{~kJ} \mathrm{~mol}^{-1}$ ) and to depend on the nature and size of the $\mathrm{R}$ substituent. This is in agreement with our expectations: the rotation about a $\mathrm{C}-\mathrm{N}$ single bond, with the nitrogen lone pair involved in the delocalized system, is about $80-100 \mathrm{~kJ} \mathrm{~mol}^{-1}$, to which must also be added the breaking of the hydrogen bond.

In Table 3 are summarized the results of all the calculations performed to access the rotational barrier $\Delta E(\mathrm{TS})$ of the transition state (TS) indicated in Fig. S11 (ESI $\dagger$ ). Whereas the deposition of zwitterions $\mathbf{6}, \mathbf{7}, \mathbf{8}, \mathbf{9}$ and $\mathbf{1 5}$ has been experimentally

Table 3 Total energies (in hartree, B3LYP/6-31+G** optimized structure for $\phi=0^{\circ}$ and $180^{\circ}$ and transition state (TS)) for the zwitterions 6 to 18 . $\Delta E(T S)=E(T S)-E\left(0^{\circ}\right)\left(\right.$ in $\left.\mathrm{kJ} \mathrm{mol}{ }^{-1}\right)$

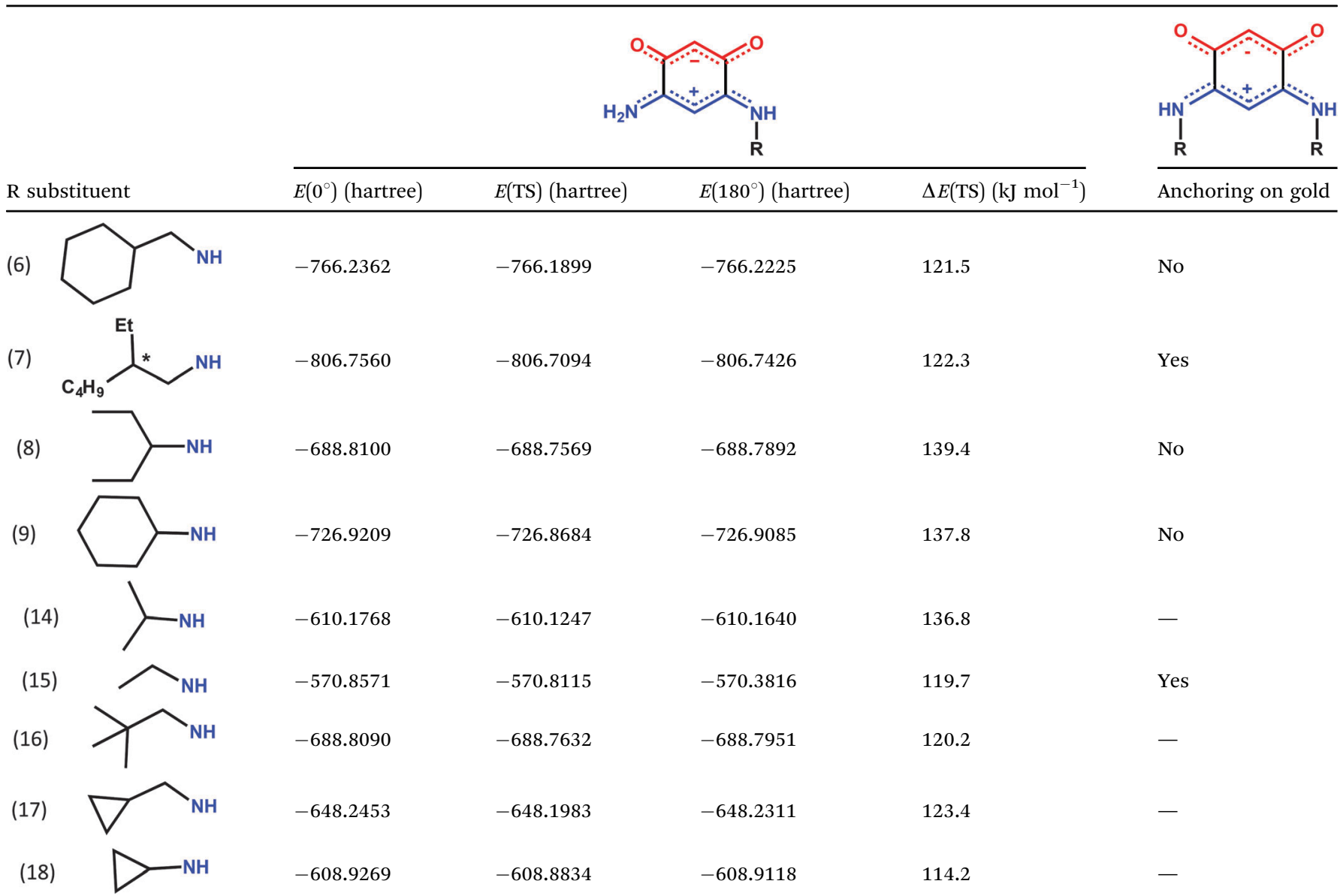


conformer B of the ethyl zwitterion 15:

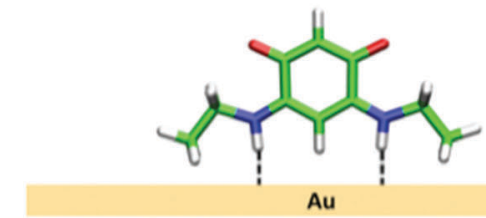

Fig. 11 Scheme of the expected anchoring of conformer B of zwitterions $\mathbf{1 5}$ and $\mathbf{6}$

investigated on the gold surface, only calculations have been carried out for comparison with zwitterions 14, 16, 17 and 18. The molecules investigated may be classified in two groups based on the analysis of the calculated rotation energies: zwitterions $\mathbf{6 , 7}$, 15-18 have a "low" $\Delta E(\mathrm{TS})$, around $120 \mathrm{~kJ} \mathrm{~mol}^{-1}$. In contrast, the energy increases significantly above $135 \mathrm{~kJ} \mathrm{~mol}^{-1}$ for zwitterions $\mathbf{8}$, 9 and 14. These results suggest that the presence of a methylene group in $\alpha$ position to the nitrogen atom significantly lowers the rotational energy around the $\mathrm{C} \cdots \mathrm{N}$ bond.

In contrast to 7 or 15, compound 6 is not anchored on the surface. This may be due, as illustrated in Fig. 11, to the steric hindrance and the low flexibility of the cyclohexyl substituent that held the nitrogen atom too far away from the surface to allow $\mathrm{N}-\mathrm{Au}$ interactions, even if conformer B can be formed.

Interestingly, none of the zwitterions having a high $\Delta E(\mathrm{TS})$ were detected by IR on the gold surface. This rotational barrier might therefore be a key parameter that determines the anchoring of the quinonoid zwitterions.

We extended our calculations to prospective zwitterions 16-18, which seem to confirm that whatever the substituent R, the rotational energy of a compound with a methylene group in $\alpha$ position to the nitrogen atom would be around $120 \mathrm{~kJ} \mathrm{~mol}^{-1}$. Zwitterion 18 can be one exception as the steric hindrance of the cyclopropyl substituent is smaller than that of the isopropyl group. Indeed zwitterion $\mathbf{1 8}$ has the same $\Delta E(\mathrm{TS})$ as the ethyl zwitterion 15 and thus a significantly smaller energy than $\mathbf{1 4}$.

The presence of a $\mathrm{CH}_{2}$ in $\alpha$ position to nitrogen thus seems to be a crucial element for the anchoring of these zwitterions on gold through $\mathrm{N}-\mathrm{Au}$ interactions. If the difference of rotational energy between anchored and not anchored molecules is significant, it remains moderate. We can speculate that performing the surface functionalization at higher temperature might allow a better anchoring of sterically hindered zwitterions.

\section{Conclusions}

This study has allowed us to enrich our library of zwitterionic, quinonoid compounds, with the synthesis of enantiopure and of sterically-hindered molecules. We found that the choice of the reaction solvent was crucial. We also observed that microwave irradiation was of high practical use for their synthesis by trans-amination reaction: this activating method allowed us to significantly increase the yields of sterically-hindered zwitterions and provided a fast ( 2 min reaction time) and efficient access to several zwitterions. For example, we successfully obtained enantiopure molecules 11, and chiral molecules 7, which were subsequently successfully deposited on a gold substrate.

This study has also allowed us to pinpoint structural and energetic criteria identifying the best candidates for molecular adhesion and coverage on gold. We have evidenced that the presence of a methylene group in $\alpha$ position to the nitrogen atom strongly influences the efficiency of the bonding through $\mathrm{N}-\mathrm{Au}$ interactions. If this is a sine-qua-non condition, the presence of a bulky and constrained substituent, like cyclohexyl, however impedes establishment of $\mathrm{N}-\mathrm{Au}$ interactions and thus the bonding of the zwitterions to a gold surface. In this case, anchoring of the molecules through the functional group (i.e. aryl interactions) should be envisaged.

Moreover, the X-ray diffraction studies performed on single crystals indicated that significant differences of the molecular arrangement were observed when the $\mathrm{R}$ alkyl substituent was modified. These results suggest that: (i) the intermolecular spacing within zwitterionic rows can be well modulated in the bulk; (ii) a study of the solid-state structures can provide insight into promising candidates for the functionalization of the metal substrate, as we know from previous studies that optimum molecules cores packing on surfaces enhances the charges transport properties.

\section{Experimental section}

\section{Synthesis}

General. Commercial 4,6-diaminoresorcinol dihydrochloride and functional amines were used directly without further purification. Solvents were freshly distilled under argon prior to use. Reactions under microwave irradiations were performed in a closed system (10 mL CEM reactor) and using a microwave CEM discover SP2011. ${ }^{1} \mathrm{H}$ NMR spectra were recorded in $\mathrm{CDCl}_{3}$ on a Bruker $500 \mathrm{MHz}$ instrument, operating at $125 \mathrm{MHz}$ for ${ }^{13} \mathrm{C}$ spectra and $500 \mathrm{MHz}$ for ${ }^{1} \mathrm{H}$ spectra. Chemical shifts are given in $\delta$ units, in parts per million (ppm) relative to the singlet at $\delta=7.26$ for $\mathrm{CHCl}_{3}$. The splittings were designated as s, singlet; $\mathrm{d}$, doublet; $\mathrm{t}$, triplet; $\mathrm{m}$, multiplet; br, broad. IR spectra were recorded in the region $4000-100 \mathrm{~cm}^{-1}$ on a Nicolet 6700 FTIR spectrometer (ATR mode, SMART ORBIT accessory, Diamond crystal).

(6Z)-4-(Hexahydrobenzylamino)-6-(hexahydrobenzyliminio)3-oxocyclohexa-1,4-dien-1-olate (6). To a suspension of the parent zwitterion $1(0.300 \mathrm{~g}, 2.17 \mathrm{mmol})$ in water $(2.5 \mathrm{~mL})$ was added 
cyclohexanemethylamine $(0.565 \mathrm{~mL}, 4.34 \mathrm{mmol})$. After microwave irradiation (the maximum power fixed at 80 Watts, 2 min at $100{ }^{\circ} \mathrm{C}$ ), the reaction mixture was filtered and the solid collected was washed several times with water. It was then dissolved in dichloromethane, the organic phase was washed with water, dried over magnesium sulfate, and filtered through Celite. The solution was concentrated under reduced pressure and addition of pentane precipitated the zwitterion 6 as a pink-violet solid (0.605 g, 84\%). ${ }^{1} \mathrm{H}$ NMR (500 MHz, $\left.\mathrm{CDCl}_{3}\right): \delta 0.96-1.05(\mathrm{~m}, 4 \mathrm{H}$, $\left.\mathrm{CH}_{2}\right), 1.12-1.30\left(\mathrm{~m}, 4 \mathrm{H}, \mathrm{CH}_{2}\right), 1.64-1.80\left(\mathrm{~m}, 14 \mathrm{H}, \mathrm{CH}\right.$ and $\left.\mathrm{CH}_{2}\right)$, $3.17\left(\mathrm{~m}, 4 \mathrm{H}, \mathrm{NCH}_{2}\right), 5.09(\mathrm{~s}, 1 \mathrm{H}, \mathrm{N} \ldots \mathrm{C} \ldots \mathrm{CH}), 5.43(\mathrm{~s}, 1 \mathrm{H}$, $\mathrm{O} \ldots \mathrm{C} . \mathrm{CH}$ ), 8.28 (br s, 2H, NH). ${ }^{13} \mathrm{C}\left\{{ }^{1} \mathrm{H}\right\}$ NMR $(125 \mathrm{MHz}$, $\left.\mathrm{CDCl}_{3}\right): \delta 25.66\left(\mathrm{~s}, \mathrm{CH}_{2}\right), 26.06\left(\mathrm{~s}, \mathrm{CH}_{2}\right), 31.04\left(\mathrm{~s}, \mathrm{CH}_{2}\right), 37.51$ (s, $\left.\mathrm{NCH}_{2} \mathrm{CH}\right), 49.59\left(\mathrm{~s}, \mathrm{NCH}_{2}\right), 80.74(\mathrm{~s}, \mathrm{~N} \ldots \mathrm{C} \ldots \mathrm{CH}), 98.74$

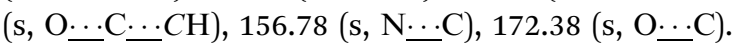

(6Z)-4-(2(Ethyl)hexylamino)-6-(2(ethyl)hexyliminio)-3-oxocyclohexa-1,4-dien-1-olate (7). To a suspension of the parent zwitterion 1 $(0.300 \mathrm{~g}, 2.17 \mathrm{mmol})$ in water $(2.5 \mathrm{~mL})$ was added 2-ethylhexylamine (0.711 mL, $4.34 \mathrm{mmol}$ ). After microwave irradiation (the maximum power fixed to 80 Watts, 2 min at $100{ }^{\circ} \mathrm{C}$ ), the reaction mixture was filtered and the solid collected was washed several times with water. It was then solubilized in dichloromethane and the organic phase was washed with water, dried over magnesium sulfate, and filtered through Celite. The solution was concentrated under reduced pressure and addition of pentane led to precipitation of the zwitterion 7 as a pink-violet solid $(0.536 \mathrm{~g}, 68 \%) .{ }^{1} \mathrm{H}$ NMR (500 MHz, $\left.\mathrm{CDCl}_{3}\right): \delta 0.89\left(\mathrm{~m}, 12 \mathrm{H}, \mathrm{CH}_{3}\right), 1.25-1.43\left(\mathrm{~m}, 16 \mathrm{H}, \mathrm{CH}_{2}\right)$, $1.67(\mathrm{~m}, 2 \mathrm{H}, \mathrm{CH}), 3.24\left(\mathrm{~m}, 4 \mathrm{H}, \mathrm{NCH}_{2}\right), 5.12(\mathrm{~s}, 1 \mathrm{H}, \mathrm{N} \ldots \mathrm{C} \ldots \mathrm{CH})$, 5.44 (s, 1H, O....CH), 8.27 (br s, 2H, NH). ${ }^{13} \mathrm{C}\left\{{ }^{1} \mathrm{H}\right\}$ NMR $\left(125 \mathrm{MHz}, \mathrm{CDCl}_{3}\right): \delta 10.87\left(\mathrm{~s}, \mathrm{CH}_{3}\right), 14.08\left(\mathrm{~s}, \mathrm{CH}_{3}\right), 22.92\left(\mathrm{~s}, \mathrm{CH}_{2}\right)$, $24.37\left(\mathrm{~s}, \mathrm{CH}_{2}\right), 28.85\left(\mathrm{~s}, \mathrm{CH}_{2}\right), 31.08\left(\mathrm{~s}, \mathrm{CH}_{2}\right), 39.00\left(\mathrm{~s}, \mathrm{NCH}_{2} \mathrm{CH}\right)$, $46.42\left(\mathrm{~s}, \mathrm{NCH}_{2}\right), 80.61$ (s, $\left.\mathrm{N} \ldots \mathrm{C} \ldots \mathrm{CH}\right), 98.80(\mathrm{~s}, \mathrm{O} \ldots \mathrm{C} \ldots \mathrm{CH})$, 156.82 (s, N...C), 172.32 (s, O..C). Anal. calcd for $\mathrm{C}_{22} \mathrm{H}_{38} \mathrm{~N}_{2} \mathrm{O}_{2}$; C, 72.88; H, 10.56; N, 7.73. Found: C, 72.58; H, 10.48; N, 7.76.

(6Z)-4-(3-Pentylamino)-6-(3-pentyliminio)-3-oxocyclohexa-1,4dien-1-olate (8). To a suspension of the parent zwitterion 1 $(0.300 \mathrm{~g}, 2.17 \mathrm{mmol})$ in water $(2.5 \mathrm{~mL})$ was added 3-aminopentane $(0.506 \mathrm{~mL}, 4.34 \mathrm{mmol})$. After microwave irradiation (the maximum power fixed at 80 Watts, $2 \mathrm{~min}$ at $100{ }^{\circ} \mathrm{C}$ ), the reaction mixture was filtered and the solid collected was washed with water $(5 \mathrm{~mL})$ and then several times with diethyl ether. The solid was solubilized in dichloromethane and the solution was filtered. The filtrate was dried over magnesium sulfate, and filtered through Celite. The solution was concentrated under reduced pressure and addition of diethyl ether led to precipitation of the zwitterion $\mathbf{8}$ as a violet solid $(0.170 \mathrm{~g}, 28 \%) .{ }^{1} \mathrm{H}$ NMR $\left(500 \mathrm{MHz}, \mathrm{CDCl}_{3}\right): \delta 0.91\left(\mathrm{t},{ }^{3} J_{\mathrm{HH}}=7.5 \mathrm{~Hz}\right.$, $\left.12 \mathrm{H}, \mathrm{CH}_{3}\right), 1.59\left(\mathrm{~m}, 4 \mathrm{H}, \mathrm{CH}_{2}\right), 1.71\left(\mathrm{~m}, 4 \mathrm{H}, \mathrm{CH}_{2}\right), 3.40(\mathrm{~m}, 2 \mathrm{H}$, $\mathrm{NCH}), 5.14$ (s, 1H, N... . . CH), 5.44 (s, 1H, O...... (br s, 2H, NH). ${ }^{13} \mathrm{C}\left\{{ }^{1} \mathrm{H}\right\} \mathrm{NMR}\left(125 \mathrm{MHz}, \mathrm{CDCl}_{3}\right): \delta 10.42\left(\mathrm{~s}, \mathrm{CH}_{3}\right)$, $27.13\left(\mathrm{~s}, \mathrm{CH}_{2}\right), 56.82(\mathrm{~s}, \mathrm{NCH}), 80.78(\mathrm{~s}, \mathrm{~N} \ldots \mathrm{C} \ldots \mathrm{CH}), 98.73$ $(\mathrm{s}, \mathrm{O} \ldots \mathrm{C} \ldots \mathrm{CH}), 156.51(\mathrm{~s}, \mathrm{~N} \ldots \mathrm{C}), 172.30$ (s, O… $)$. Anal. calcd for $\mathrm{C}_{16} \mathrm{H}_{26} \mathrm{~N}_{2} \mathrm{O}_{2}, 0.1 \mathrm{H}_{2} \mathrm{O} ; \mathrm{C}, 68.59 ; \mathrm{H}, 9.42 ; \mathrm{N}, 10.00$. Found: $\mathrm{C}$, 68.23; H, 9.32; N, 10.03 .

(6Z)-4-(Cyclohexylamino)-6-(cyclohexyliminio)-3-oxocyclohexa1,4-dien-1-olate (9). To a suspension of the parent zwitterion 1 $(0.300 \mathrm{~g}, 2.17 \mathrm{mmol})$ in water $(2.5 \mathrm{~mL})$ was added cyclohexylamine
(0.495 $\mathrm{mL}, 4.34 \mathrm{mmol}$ ). After microwave irradiation (the maximum power fixed at 80 Watts, $1 \mathrm{~min}$ at $100{ }^{\circ} \mathrm{C}$ ), the reaction mixture was filtered and the solid collected was washed several times with water. It was the dissolved in dichloromethane and the organic phase was washed with water, dried over magnesium sulfate, and filtered through Celite. The solution was concentrated under reduced pressure and addition of pentane led to precipitation of the zwitterion 9 as a red solid $(0.495 \mathrm{~g}, 76 \%) .{ }^{1} \mathrm{H}$ NMR $(500 \mathrm{MHz}$, $\left.\mathrm{CDCl}_{3}\right): \delta 1.27\left(\mathrm{~m}, 2 \mathrm{H}, \mathrm{CH}_{2}\right), 1.41\left(\mathrm{~m}, 8 \mathrm{H}, \mathrm{CH}_{2}\right), 1.66(\mathrm{~m}, 2 \mathrm{H}$, $\left.\mathrm{CH}_{2}\right), 1.82\left(\mathrm{~m}, 4 \mathrm{H}, \mathrm{CH}_{2}\right), 1.94\left(\mathrm{~m}, 4 \mathrm{H}, \mathrm{CH}_{2}\right), 3.49(\mathrm{~m}, 2 \mathrm{H}, \mathrm{CH})$, $5.10(\mathrm{~s}, 1 \mathrm{H}, \mathrm{N} \ldots \mathrm{C} \ldots \mathrm{CH}), 5.44(\mathrm{~s}, 1 \mathrm{H}, \mathrm{O} \ldots \mathrm{C} \ldots \mathrm{CH}), 8.15$ (br s, $2 \mathrm{H}, \mathrm{NH}) .{ }^{13} \mathrm{C}\left\{{ }^{1} \mathrm{H}\right\}$ NMR (125 MHz, $\left.\mathrm{CDCl}_{3}\right): \delta 24.33\left(\mathrm{~s}, \mathrm{CH}_{2}\right), 25.09$ $\left(\mathrm{s}, \mathrm{CH}_{2}\right), 31.93\left(\mathrm{~s}, \mathrm{CH}_{2}\right), 52.09(\mathrm{~s}, \mathrm{NCH}), 80.44(\mathrm{~s}, \mathrm{~N} \ldots \mathrm{C} \ldots \mathrm{CH})$, 99.04 (s, O...... calcd for $\mathrm{C}_{18} \mathrm{H}_{26} \mathrm{~N}_{2} \mathrm{O}_{2}, 0.1 \mathrm{H}_{2} \mathrm{O} ; \mathrm{C}, 71.07 ; \mathrm{H}, 8.68 ; \mathrm{N}, 9.21$. Found: C, 70.96; H, 8.67; N, 9.26.

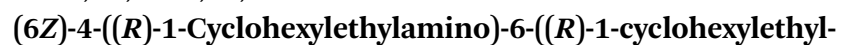
iminio)-3-oxocyclohexa-1,4-dien-1-olate (10). To a suspension of the parent zwitterion $1(0.300 \mathrm{~g}, 2.17 \mathrm{mmol})$ in water $(10 \mathrm{~mL})$ was added $(R)-(-)-1$-cyclohexylethylamine $(0.638 \mathrm{~mL}, 4.34 \mathrm{mmol})$. The solution was heated at $100{ }^{\circ} \mathrm{C}$ for $2 \mathrm{~h}$ (preheated oil bath). After cooling to room temperature, the reaction mixture was filtered and the solid was washed several times with water. It was solubilized in dichloromethane and the organic phase was washed with water, dried over magnesium sulfate, and filtered through Celite. The solution was concentrated under reduced pressure and addition of pentane led to precipitation of the zwitterion 10 as a violet solid $(0.465 \mathrm{~g}, 60 \%) .{ }^{1} \mathrm{H}$ NMR $(500 \mathrm{MHz}$, $\left.\mathrm{CDCl}_{3}\right): \delta 0.91-1.30\left(\mathrm{~m}, 10 \mathrm{H}, \mathrm{CH}_{2}\right), 1.26\left(\mathrm{~d},{ }^{3} \mathrm{~J}_{\mathrm{HH}}=6.6 \mathrm{~Hz}, 6 \mathrm{H}\right.$, $\left.\mathrm{CH}_{3}\right), 1.50(\mathrm{~m}, 2 \mathrm{H}, \mathrm{NCHCH}), 1.67-1.82\left(\mathrm{~m}, 10 \mathrm{H}, \mathrm{CH}_{2}\right), 3.45(\mathrm{~m}$, $2 \mathrm{H}, \mathrm{NCH}), 5.08(\mathrm{~s}, 1 \mathrm{H}, \mathrm{N} \ldots \mathrm{C} \ldots \mathrm{CH}), 5.46(\mathrm{~s}, 1 \mathrm{H}, \mathrm{O} \ldots \mathrm{C} \ldots \mathrm{CH})$, 8.13 (br s, 2H, NH). ${ }^{13} \mathrm{C}\left\{{ }^{1} \mathrm{H}\right\}$ NMR (125 MHz, $\left.\mathrm{CDCl}_{3}\right): \delta 17.34$ (s, $\left.\mathrm{CH}_{3}\right), 25.97$ (s, $\left.\mathrm{CH}_{2}\right), 26.09$ (s, $\left.\mathrm{CH}_{2}\right), 29.19$ (s, $\left.\mathrm{CH}_{2}\right), 29.33\left(\mathrm{~s}, \mathrm{CH}_{2}\right)$, 43.16 (s, NCHCH), 54.19 (s, NCH), 80.52 (s, N......

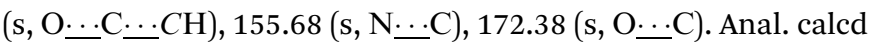
for $\mathrm{C}_{22} \mathrm{H}_{34} \mathrm{~N}_{2} \mathrm{O}_{2}, 0.5 \mathrm{H}_{2} \mathrm{O} ; \mathrm{C}, 71.90 ; \mathrm{H}, 9.60 ; \mathrm{N}, 7.62$. Found: $\mathrm{C}$, 71.86; H, 9.56; N, 7.63.

$(6 Z)-4-((S)-1,2,3,4-T e t r a h y d r o-1-n a p h t h y l a m i n o)-6-((S)-1,2,3,4-$ tetrahydro-1-naphthyliminio)-3-oxocyclohexa-1,4-dien-1-olate (11). To a suspension of the parent zwitterion $1(0.300 \mathrm{~g}, 2.17 \mathrm{mmol})$ in water $(2.5 \mathrm{~mL})$ was added $(S)-(+)-1,2,3,4$-tetrahydro-1-naphthylamine $(0.618 \mathrm{~mL}, 4.34 \mathrm{mmol})$. After microwave irradiation (the maximum power fixed at $80 \mathrm{Watts}, 2 \mathrm{~min}$ at $100{ }^{\circ} \mathrm{C}$ ), the reaction mixture was filtered and the solid collected was washed several times with water. It was solubilized in dichloromethane and the organic phase was washed with water, dried over magnesium sulfate, and filtered through Celite. The solution was concentrated under reduced pressure and addition of pentane led to precipitation of the zwitterion 11 as a pink-violet solid $(0.528 \mathrm{~g}$, 61\%). ${ }^{1} \mathrm{H}$ NMR (500 MHz, $\left.\mathrm{CDCl}_{3}\right): \delta$ 1.82-2.09 (m, 6H, $\mathrm{CH}_{2}$ ), 2.10-2.16 (m, 2H, $\left.\mathrm{CH}_{2}\right), 2.85\left(\mathrm{~m}, 4 \mathrm{H}, \mathrm{CH}_{2}\right), 4.85(\mathrm{~m}, 2 \mathrm{H}, \mathrm{NCH})$, 5.48 (s, 1H, N.C...CH), 5.50 (s, 1H, O.C...CH), 7.10-7.26 $\left(\mathrm{m}, 8 \mathrm{H}, \mathrm{CH}_{\mathrm{Ar}}\right.$ ), 8.49 (br s, 2H, NH). ${ }^{13} \mathrm{C}\left\{{ }^{1} \mathrm{H}\right\} \mathrm{NMR}(125 \mathrm{MHz}$, $\left.\mathrm{CDCl}_{3}\right): \delta 19.90\left(\mathrm{~s}, \mathrm{CH}_{2}\right), 28.83\left(\mathrm{~s}, \mathrm{CH}_{2}\right), 29.22\left(\mathrm{~s}, \mathrm{CH}_{2}\right), 52.08$ (s, NCH), 80.75 (s, N...... $\left(\mathrm{s}, \mathrm{CH}_{\mathrm{Ar}}\right), 128.61\left(\mathrm{~s}, \mathrm{CH}_{\mathrm{Ar}}\right), 129.79\left(\mathrm{~s}, \mathrm{CH}_{\mathrm{Ar}}\right), 132.95\left(\mathrm{~s}, \mathrm{C}_{\mathrm{quat} A r}\right)$, 
137.52 (s, $\mathrm{C}_{\text {quat Ar}}$ ), 155.89 (s, N...C), 172.13 (s, O...C). Anal. calcd for $\mathrm{C}_{26} \mathrm{H}_{26} \mathrm{~N}_{2} \mathrm{O}_{2}, 0.5 \mathrm{H}_{2} \mathrm{O} ; \mathrm{C}, 76.63 ; \mathrm{H}, 6.68 ; \mathrm{N}, 6.87$. Found: C, 76.69; H, 6.49; N, 6.88 .

(6Z)-4-(1-Indanamino)-6-(1-indaniminio)-3-oxocyclohexa-1,4dien-1-olate (12). To a suspension of the parent zwitterion 1 $(0.300 \mathrm{~g}, 2.17 \mathrm{mmol})$ in water $(2.5 \mathrm{~mL})$ was added 1-aminoindane $(0.557 \mathrm{~mL}, 4.34 \mathrm{mmol})$. After microwave irradiation (the maximum power fixed at 80 Watts, 2 min at $100{ }^{\circ} \mathrm{C}$ ), the reaction mixture was filtered and the solid was washed several times with water. The solid was solubilized in dichloromethane and the organic phase was washed with water, dried over magnesium sulfate, and filtered through Celite. The solution was concentrated under reduced pressure and addition of pentane led to precipitation of the zwitterion 12 as a violet solid $(0.260 \mathrm{~g}, 28 \%) .{ }^{1} \mathrm{H}$ NMR $(500 \mathrm{MHz}$, $\left.\mathrm{CDCl}_{3}\right): \delta 2.05\left(\mathrm{~m}, 2 \mathrm{H}, \mathrm{CH}_{2}\right), 2.55\left(\mathrm{~m}, 2 \mathrm{H}, \mathrm{CH}_{2}\right), 2.91\left(\mathrm{~m}, 2 \mathrm{H}, \mathrm{CH}_{2}\right)$, $3.04\left(\mathrm{~m}, 2 \mathrm{H}, \mathrm{CH}_{2}\right), 5.11(\mathrm{~m}, 2 \mathrm{H}, \mathrm{NCH}), 5.43(\mathrm{~s}, 1 \mathrm{H}, \mathrm{O} \ldots \mathrm{C} \ldots \mathrm{CH})$, $5.46(\mathrm{~m}, 1 \mathrm{H}, \mathrm{N} \ldots \mathrm{C} \ldots \mathrm{CH}), 7.16-7.27\left(\mathrm{~m}, 8 \mathrm{H}, \mathrm{CH}_{\mathrm{Ar}}\right), 8.41$ (br s, $2 \mathrm{H}, \mathrm{NH}) .{ }^{13} \mathrm{C}\left\{{ }^{1} \mathrm{H}\right\}$ NMR (125 MHz, $\left.\mathrm{CDCl}_{3}\right): \delta 30.50\left(\mathrm{~s}, \mathrm{CH}_{2}\right)$, $32.96\left(\mathrm{~s}, \mathrm{CH}_{2}\right), 58.58$ (s, NCH), 81.85 (s, N...... $(\mathrm{s}, \mathrm{O} \ldots \mathrm{C} \ldots \mathrm{CH}), 124.30\left(\mathrm{~s}, \mathrm{CH}_{\mathrm{Ar}}\right), 124.36\left(\mathrm{~s}, \mathrm{CH}_{\mathrm{Ar}}\right), 125.4\left(\mathrm{~s}, \mathrm{CH}_{\mathrm{Ar}}\right)$, $127.41\left(\mathrm{~s}, \mathrm{CH}_{\mathrm{Ar}}\right), 129.30\left(\mathrm{~s}, \mathrm{CH}_{\mathrm{Ar}}\right), 129.33\left(\mathrm{~s}, \mathrm{CH}_{\mathrm{Ar}}\right), 139.68$ ( $\mathrm{s}, \mathrm{C}_{\text {quat Ar }}$ ), 139.78 (s, $\left.\mathrm{C}_{\text {quat Ar }}\right), 143.42\left(\mathrm{~s}, \mathrm{C}_{\text {quat Ar}}\right), 143.44\left(\mathrm{~s}, \mathrm{C}_{\text {quat Ar }}\right.$ ), 156.40 (s, N...C), 172.11 (s, O...C).

(6Z)-4-(2-Indanamino)-6-(2-indaniminio)-3-oxocyclohexa-1,4dien-1-olate (13). To a suspension of the parent zwitterion 1 $(0.300 \mathrm{~g}, 2.17 \mathrm{mmol})$ in water $(2.5 \mathrm{~mL})$ was added 2-aminoindane (0.565 mL, $4.34 \mathrm{mmol}$ ). After microwave irradiation (the maximum power fixed at 80 Watts, $2 \mathrm{~min}$ at $100{ }^{\circ} \mathrm{C}$ ), the reaction mixture was filtered and the solid collected was washed several times with water. It was the dissolved in dichloromethane and the organic phase was washed with water, dried over magnesium sulfate, and filtered through Celite. The solution was concentrated under reduced pressure and addition of pentane led to precipitation of the zwitterion 13 as a green solid (0.705 g, 87\%). ${ }^{1} \mathrm{H}$ NMR (500 $\left.\mathrm{MHz}, \mathrm{CDCl}_{3}\right)$ : $\delta 3.08\left(\mathrm{dd},{ }^{3} J_{\mathrm{HH}}=4.7 \mathrm{~Hz}\right.$ and $\left.{ }^{2} J_{\mathrm{AB}}=16.2 \mathrm{~Hz}, 4 \mathrm{H}, \mathrm{CH}_{2}\right), 3.42\left(\mathrm{dd},{ }^{3} J_{\mathrm{HH}}=\right.$ $7.2 \mathrm{~Hz}$ and $\left.{ }^{2} J_{\mathrm{AB}}=16.0 \mathrm{~Hz}, 4 \mathrm{H}, \mathrm{CH}_{2}\right), 4.47(\mathrm{~m}, 2 \mathrm{H}, \mathrm{NCH}), 5.32(\mathrm{~s}, 1 \mathrm{H}$, $\mathrm{N} \ldots \mathrm{C} \ldots \mathrm{CH}$ ), 5.43 (s, 1H, O…… 8.41 (br s, 2H, NH). ${ }^{13} \mathrm{C}\left\{{ }^{1} \mathrm{H}\right\} \mathrm{NMR}\left(125 \mathrm{MHz}, \mathrm{CDCl}_{3}\right): \delta 39.43\left(\mathrm{~s}, \mathrm{CH}_{2}\right)$, $54.11(\mathrm{~s}, \mathrm{NCH}), 81.52(\mathrm{~s}, \mathrm{~N} \ldots \mathrm{C} \ldots \mathrm{CH}), 99.06(\mathrm{~s}, \mathrm{O} \ldots \mathrm{C} \ldots \mathrm{CH}), 124.94$ $\left(\mathrm{s}, \mathrm{CH}_{\mathrm{Ar}}\right), 127.61\left(\mathrm{~s}, \mathrm{CH}_{\mathrm{Ar}}\right), 139.24$ (s, $\left.\mathrm{C}_{\text {quat Ar }}\right), 156.29$ (s, N...C), $171.98(\mathrm{~s}, \mathrm{O}$...C).

\section{Crystal structure determinations}

X-ray diffraction data were collected on a Kappa CCD diffractometer using graphite-monochromated Mo-K $\alpha$ radiation $(\lambda=$ $0.71073 \AA$ A ) (Table S1, ESI $\dagger$ ). Data were collected using $\psi$ scans, the structures were solved by direct methods using the SHELX97 software, ${ }^{19}$ and the refinement was by full-matrix least squares on $F^{2}$. No absorption or self-absorption correction was used. All non-hydrogen atoms were refined anisotropically, with $\mathrm{H}$ atoms introduced as fixed contributors $\left(d(\mathrm{C}-\mathrm{H})=0.95 \AA, U_{11}=0.04\right)$. CCDC 1437115-1437117.

\section{Functionalization of the gold surfaces}

The zwitterionic molecules were deposited on clean gold substrates from a $\mathrm{CH}_{2} \mathrm{Cl}_{2}$ solution. Typical overnight exposure to a
$0.8 \mathrm{mmol}$ solution $\left(0.2 \mathrm{~g} \mathrm{l}^{-1}\right)$ was followed by extensive ethanol washing to remove the excess molecules not bonded to the Au substrate (to remove drops of solution on the surface, the functionalized surface was dipped into ethanol. Then the surface was immersed during one minute in $3 \mathrm{~mL}$ of absolute ethanol. This latest operation was repeated two more times, and fresh ethanol was used each time). The samples were dried and kept under nitrogen atmosphere.

\section{IR measurements of gold surfaces}

Samples were analyzed with an Equinox 55 (Bruker Optics) spectrometer equipped with an air-cooled Globar mid-IR (MIR) source, a deuterated triglycine sulfate detector and a singlereflection attenuated total reflectance (ATR) MIRacle ${ }^{\circledR}$ module with $\mathrm{ZnSe}$ contact crystal (Pike Technologies). Spectra were recorded (128 scans) from 4000 to $610 \mathrm{~cm}^{-1}$ at a resolution of $4 \mathrm{~cm}^{-1}$ using Opus NT version 6.5 (Bruker Optics).

\section{Theoretical calculations for IR spectra}

Theoretical calculations were performed to model the zwitterion vibrational modes using the SPARTAN density functional theory (DFT) $a b$ initio package, using the hybrid B3LYP functional. Calculations were undertaken with the standard 3-21G basis set. The initial geometry was chosen by assigning the molecule to the $C_{2 \mathrm{v}}$ symmetry point group and standard bond lengths and then the geometry was optimized at the self-consistent field (SCF) level and further refined at the SCF-3-21G level. The solutions of the improved force field calculations provided the vibrational frequencies of zwitterions summarized in Fig. 7 and 8.

The calculations were performed in several ways, with extended and selected, more limited, basis sets and checked again using more limited modified neglect of differential overlap (MNDO) calculations, as well as DFT with and without the generalized gradient approximation (GGA). The theoretical analysis presented in this paper for the vibrational modes results from the application of density functional theory with the 6-21G basis set following geometry optimization, but the various theoretical approaches generally provided very similar outcomes. Note that we did not detail in this paper all the theory and various approaches used for modeling the vibrational modes since it did not add much in terms of new insights. The main flaw in the calculations is that none of the models or methodologies included anharmonic corrections to the vibrational modes, but we regard such an effort as beyond the scope of this paper.

\section{Computational details}

Calculations (energies and geometries) have been optimised at the density functional theory (DFT) level with the hybrid B3LYP exchange-correlation functional as implemented in the Gaussian 09 program. ${ }^{20}$ The all electron $6-31+\mathrm{G}^{*(*)}$ set of basis functions was then used for all atoms. These parameters are coherent with previous calculations performed on similar molecules. ${ }^{10 a}$ Optimization were also performed with the gradient corrected density functional $\mathrm{BP} 86^{21}$ and with the Hartree Fock (HF) for comparison. 
In order to access the rotation barrier around the $\mathrm{C}-\mathrm{N}$ bond of the zwitterion and then the transition state (TS, see Fig. S11, ESI $\dagger$ ), we performed constrained geometry optimizations as a function of dihedral angles with the Modredundant option (Relaxed Potential Energy Scan) of Gaussian 09. The $\phi$ dihedral was increased from 0 to 180 by 10 degrees. Each time the geometry was optimized with the constrained dihedral angle, the angle was again increased by the same amount. We then chose the geometry of maximum energy and submitted this to a restricted transition state calculation in order to access the energy and geometry of the TS between the two conformations of the zwitterion. Transition states were characterized by a single imaginary frequency and visual inspection of the corresponding vibrational modes ensured that the desired minima are connected. These calculations were carried out on zwitterions with one substituent $\mathrm{R}$ on one $\mathrm{N}$ only to gain calculation time.

\section{Acknowledgements}

This research was supported by the Centre National de la Recherche Scientifique and the Ministère de la Recherche et des Nouvelles Technologies (Paris), the ANR (07-BLAN-0274-04), the National Science Foundation through the Nebraska Center for Materials and Nanoscience at the University of Nebraska-Lincoln (DMR-1420645).

\section{References}

1 See for examples: (a) G. Witte and C. Woell, Phase Transitions, 2003, 76, 291-305; (b) S. De Feyter and F. C. De Schryver, J. Phys. Chem. B, 2005, 109, 4290-4302; (c) J. C. Love, L. A. Estroff, J. K. Kriebel, R. G. Nuzzo and G. M. Whitesides, Chem. Rev., 2005, 105, 1103-1169; (d) J. Zhang, Q. Chi, T. Albrecht, A. M. Kuznetsov, M. Grubb, A. G. Hansen, H. Wackerbarth, A. C. Welinder and J. Ulstrup, Electrochim. Acta, 2005, 50, 3143-3159; (e) M. Hietschold, M. Lackinger, S. Griessl, W. M. Heckl, T. G. Gopakumar and G. W. Flynn, Microelectron. Eng., 2005, 82, 207-214; $(f)$ M.-a. Haga, K. Kobayashi and K. Terada, Coord. Chem. Rev., 2007, 251, 2688-2701; $(g)$ G. M. Rangger, L. Romaner, G. Heimel and E. Zojer, Surf. Interface Anal., 2008, 40, 371-378; (h) M. Kind and C. Woell, Chem. Unserer Zeit, 2008, 42, 128-141; (i) D. P. Woodruff, Phys. Chem. Chem. Phys., 2008, 10, 7211-7221; $(j)$ G. Heimel, L. Romaner, E. Zojer and J.-L. Bredas, Acc. Chem. Res., 2008, 41, 721-729; $(k)$ E. Pensa, E. Cortes, G. Corthey, P. Carro, C. Vericat, M. H. Fonticelli, G. Benitez, A. A. Rubert and R. C. Salvarezza, Acc. Chem. Res., 2011, 45, 1183-1192; ( l ) L. Kong, F. Chesneau, Z. Zhang, F. Staier, A. Terfort, P. A. Dowben and M. Zharnikov, J. Phys. Chem. C, 2011, 115, 22422-22428; ( $m$ ) J. L. Zhang, T. C. Niu, A. T. S. Wee and W. Chen, Phys. Chem. Chem. Phys., 2013, 15, 12414-12427; (n) K. T. Wong and N. S. Lewis, Acc. Chem. Res., 2014, 47, 3037-3044; (o) C. Vericat, M. E. Vela, G. Corthey, E. Pensa, E. Cortes, M. H. Fonticelli, F. Ibanez,
G. E. Benitez, P. Carro and R. C. Salvarezza, RSC Adv., 2014, 4, 27730-27754; (p) B. E. Hirsch, K. P. McDonald, B. Qiao, A. H. Flood and S. L. Tait, ACS Nano, 2014, 8, 10858-10869; (q) Q. Guo and F. Li, Phys. Chem. Chem. Phys., 2014, 16, 19074-19090; (r) E. Benassi and S. Corni, J. Phys. Chem. C, 2014, 118, 25906-25917; (s) D. Thompson, J. Liao, M. Nolan, A. J. Quinn, C. A. Nijhuis, C. O'Dwyer, P. N. Nirmalraj, C. Schonenberger and M. Calame, J. Phys. Chem. C, 2015, 119, 19438-19451; $(t)$ K. Sun, M. Lan and J.-Z. Wang, Phys. Chem. Chem. Phys., 2015, 17, 26220-26224; (u) F. Blobner, P. N. Abufager, R. Han, J. Bauer, D. A. Duncan, R. J. Maurer, K. Reuter, P. Feulner and F. Allegretti, J. Phys. Chem. C, 2015, 119, 15455-15468; (v) T. Niu, Appl. Phys. Lett., 2015, 106, 161601.

2 See for examples: (a) M. Wanunu, A. Vaskevich, A. Shanzer and I. Rubinstein, J. Am. Chem. Soc., 2006, 128, 8341-8349; (b) R. Cao Jr, A. M. Diaz-Garcia and R. Cao, Coord. Chem. Rev., 2009, 253, 1262-1275; (c) T. Kurita, Y. Nishimori, F. Toshimitsu, S. Muratsugu, S. Kume and H. Nishihara, J. Am. Chem. Soc., 2010, 132, 4524-4525; (d) M. D. Yilmaz and J. Huskens, Soft Matter, 2012, 8, 11768-11780; (e) S. Richter, J. Poppenberg, C. H.-H. Traulsen, E. Darlatt, A. Sokolowski, D. Sattler, W. E. S. Unger and C. A. Schalley, J. Am. Chem. Soc., 2012, 134, 16289-16297; $(f)$ A. Hayoun Barak, G. de Ruiter, M. Lahav, S. Sharma, O. Gidron, G. Evmenenko, P. Dutta, M. Bendikov and M. E. van der Boom, Chem. - Eur. J., 2013, 19, 8821-8831; $(g)$ G. de Ruiter, M. Lahav, G. Evmenenko, P. Dutta, D. A. Cristaldi, A. Gulino and M. E. van der Boom, J. Am. Chem. Soc., 2013, 135, 16533-16544; (h) R. Sakamoto, S. Katagiri, H. Maeda and H. Nishihara, Coord. Chem. Rev., 2013, 257, 1493-1506; (i) N. Giamblanco, N. Tuccitto, G. Zappala, G. Sfuncia, A. Licciardello and G. Marletta, ACS Appl. Mater. Interfaces, 2015, 7, 23353-23363; (j) A. S. Benson, M. B. Elinski, M. L. Ohnsorg, C. K. Beaudoin, K. A. Alexander, G. F. Peaslee, P. A. DeYoung and M. E. Anderson, Thin Solid Films, 2015, 590, 103-110.

3 See for examples: (a) S. M. Williams, K. R. Rodriguez, S. Teeters-Kennedy, S. Shah, T. M. Rogers, A. D. Stafford and J. V. Coe, Nanotechnology, 2004, 15, S495-S503; (b) S. Szunerits, S. E. Pust and G. Wittstock, Anal. Bioanal. Chem., 2007, 389, 1103-1120; (c) S. Baldelli, ChemPhysChem, 2008, 9, 2291-2298; (d) J. A. Carter, Z. Wang and D. D. Dlott, Acc. Chem. Res., 2009, 42, 1343-1351; (e) K. Ataka, S. T. Stripp and J. Heberle, Biochim. Biophys. Acta, 2013, 1828, 2283-2293; $(f)$ J. Hu, M. Tanabe, J. Sato, K. Uosaki and K. Ikeda, J. Am. Chem. Soc., 2014, 136, 10299-10307; (g) D. Jiang, W. Zhou, X. Zhong, Y. Zhang and X. Li, ACS Appl. Mater. Interfaces, 2014, 6, 10958-10962; (h) C. M. Berg, Y. Sun and D. D. Dlott, J. Phys. Chem. B, 2014, 118, 7770-7776; ( $i$ ) M. C. Fletcher, D. M. Alexson, M. M. Moore, S. M. Prokes, O. Glembocki, A. Vivoni, R. McCoy, S. Mishra, P. Tandon and C. M. Hosten, J. Mol. Struct., 2015, 1099, 534-542; $(j)$ M. Benounis, N. Jaffrezic, C. Martelet, I. Dumazet-Bonnamour and R. Lamartine, Mater. Trans., 2015, 56, 539-544. 
4 See for examples: (a) J. Mathiyarasu, S. S. Pathak and V. Yegnaraman, Corros. Rev., 2006, 24, 307-322; (b) M. I. Muglali, A. Bashir and M. Rohwerder, Phys. Status Solidi A, 2010, 207, 793-800; (c) S. Meth, N. Savchenko, M. Koltypin, D. Starosvetsky, F. A. Viva, A. Groysman and C. N. Sukenik, Corros. Sci., 2010, 52, 125-129; (d) S. Meth, N. Savchenko, F. A. Viva, D. Starosvetsky, A. Groysman and C. N. Sukenik, J. Appl. Electrochem., 2011, 41, 885-890; (e) I. R. Fernando, S. Jianrattanasawat, N. Daskalakis, K. D. Demadis and G. Mezei, CrystEngComm, 2012, 14, 908-919; $(f)$ S. K. Tiwari, M. Tripathi and R. Singh, Corros. Sci., 2012, 63, 334-341; (g) M. Abdallah, B. H. Asghar, I. Zaafarany and M. Sobhi, Prot. Met., 2013, 49, 485-491; (h) S. Hosseinpour, M. Goethelid, C. Leygraf and C. M. Johnson, J. Electrochem. Soc., 2014, 161, C50-C56; (i) T. Abohalkuma and J. Telegdi, Mater. Corros., 2015, 66, 1382-1390; $(j)$ R. Bhargava, T. Daeneke, S. J. Thompson, J. Lloyd, C.-A. Palma, J. Reichert, J. V. Barth, L. Spiccia and U. Bach, J. Phys. Chem. C, 2015, 119, 19613-19618.

5 See for examples: (a) D. Giust, J. L. Albasanz, M. Martin, R. Marega, A. Delforge and D. Bonifazi, Chem. Commun., 2011, 47, 10617-10619; (b) N. J. Hickok and I. M. Shapiro, Adv. Drug Delivery Rev., 2012, 64, 1165-1176; (c) N. Meyerbroeker, Z.-A. Li, W. Eck and M. Zharnikov, Chem. Mater., 2012, 24, 2965-2972; (d) G. Dacarro, L. Cucca, P. Grisoli, P. Pallavicini, M. Patrini and A. Taglietti, Dalton Trans., 2012, 41, 2456-2463; (e) I. M. Shapiro, N. J. Hickok, J. Parvizi, S. Stewart and T. P. Schaer, Eur. Cells Mater., 2012, 23, 362-370; $(f)$ J. Maciel, M. I. Oliveira, R. M. Goncalves and M. A. Barbosa, Acta Biomater., 2012, 8, 3669-3677; $(g)$ E.-B. Ko, H.-Y. Cho, T.-H. Kim, C.-H. Yea and J.-W. Choi, Colloids Surf., B, 2013, 112, 387-392; (h) X.-L. Yu, S.-J. Xu, J.-D. Shao, C. Du, S.-F. Chen, B. Zhang, Y.-X. Wang and X.-M. Wang, Surf. Coat. Technol., 2013, 228, S48-S54; (i) Z. Grubac, M. Metikos-Hukovic, R. Babic, I. S. Roncevic, M. Petravic and R. Peter, Mater. Sci. Eng., C, 2013, 33, 2152-2158; $(j)$ K. M. Kruszewski, L. Nistico, M. J. Longwell, M. J. Hynes, J. A. Maurer, L. Hall-Stoodley and E. S. Gawalt, Mater. Sci. Eng., C, 2013, 33, 2059-2069; (k) S. B. Goodman, Z. Yao, M. Keeney and F. Yang, Biomaterials, 2013, 34, 3174-3183; (l) R. A. Surmenev, M. A. Surmeneva and A. A. Ivanova, Acta Biomater., 2014, 10, 557-579.

6 See for examples: (a) N. K. Chaki and K. Vijayamohanan, Biosens. Bioelectron., 2002, 17, 1-12; (b) J. J. Gooding, Electroanalysis, 2008, 20, 573-582; (c) N. Ilk, E. M. Egelseer, J. Ferner-Ortner, S. Kuepcue, D. Pum, B. Schuster and U. B. Sleytr, Colloids Surf., A, 2008, 321, 163-167; (d) C. Ley, D. Holtmann, K.-M. Mangold and J. Schrader, Colloids Surf., B, 2011, 88, 539-551; (e) Y. Egawa, T. Seki, S. Takahashi and J.-I. Anzai, Mater. Sci. Eng., C, 2011, 31, 1257-1264; $(f)$ A. Tada, Y. Geng, M. Nakamura, Q. Wei, K. Hashimoto and K. Tajima, Phys. Chem. Chem. Phys., 2012, 14, 3713-3724; $(g)$ G. Guerrero, J. G. Alauzun, M. Granier, D. Laurencin and P. H. Mutin, Dalton Trans., 2013, 42, 12569-12585.
7 See for examples: (a) H. Ishii, K. Sugiyama, E. Ito and K. Seki, Adv. Mater., 1999, 11, 605-625; (b) N. Koch, ChemPhysChem, 2007, 8, 1438-1455; (c) H. Ma, H.-L. Yip, F. Huang and A. K.-Y. Jen, Adv. Funct. Mater., 2010, 20, 1371-1388.

8 K. Asadi, F. Gholamrezaie, E. C. P. Smits, P. W. M. Blom and B. de Boer, J. Mater. Chem., 2007, 17, 1947-1953.

9 (a) J. Xiao, Z. Zhang, D. Wu, L. Routaboul, P. Braunstein, B. Doudin, Y. B. Losovyj, O. Kizilkaya, L. G. Rosa, C. N. Borca, A. Gruverman and P. A. Dowben, Phys. Chem. Chem. Phys., 2010, 12, 10329-10340; (b) Z. Zhang, J. Alvira, X. Barbosa, L. G. Rosa, L. Routaboul, P. Braunstein, B. Doudin and P. A. Dowben, J. Phys. Chem. C, 2011, 115, 2812-2818; (c) L. G. Rosa, J. Velev, Z. Zhang, J. Alvira, O. Vega, G. Diaz, L. Routaboul, P. Braunstein, B. Doudin, Y. B. Losovyj and P. A. Dowben, Phys. Status Solidi B, 2012, 249, 1571-1576; (d) L. Routaboul, P. Braunstein, J. Xiao, Z. Zhang, P. A. Dowben, G. Dalmas, V. Da Costa, O. Felix, G. Decher, L. G. Rosa and B. Doudin, J. Am. Chem. Soc., 2012, 134, 8494-8506; (e) P. A. Dowben, D. A. Kunkel, A. Enders, L. G. Rosa, L. Routaboul, B. Doudin and P. Braunstein, Top. Catal., 2013, 56, 1096-1103.

10 (a) P. Braunstein, O. Siri, J.-P. Taquet, M.-M. Rohmer, M. Bénard and R. Welter, J. Am. Chem. Soc., 2003, 125, 12246-12256; (b) P. Braunstein, O. Siri and J.-P. Taquet, Benzoquinone monoimine derivatives, synthesis process, coloring compositions containing them, and uses of the latter, especially for hair coloring, WO 2004009534 A1, 2004; (c) J.-P. Taquet, O. Siri, P. Braunstein and R. Welter, Inorg. Chem., 2004, 43, 6944-6953; (d) Q.-Z. Yang, O. Siri and P. Braunstein, Chem. - Eur. J., 2005, 11, 7237-7246; (e) P. Braunstein, O. Siri, P. Steffanut, M. Winter and Q.-Z. Yang, C. R. Chim., 2006, 9, 1493-1499; $(f)$ Q.-Z. Yang, A. Kermagoret, M. Agostinho, O. Siri and P. Braunstein, Organometallics, 2006, 25, 5518-5527; $(g)$ M. Yuan, F. Weisser, B. Sarkar, A. Garci, P. Braunstein, L. Routaboul and B. Therrien, Organometallics, 2014, 33, 5043-5045; (h) A. Ghisolfi, A. Waldvogel, L. Routaboul and P. Braunstein, Inorg. Chem., 2014, 53, 5515-5526.

11 B. Doudin, P. Braunstein, L. Routaboul, G. Dalmas, Z. Zhang and P. A. Dowben, Use of zwitterionic molecules for forming a hole or electron transport layer, European Patent Office, WO 2012025878 A1, 2012.

12 (a) D. A. Kunkel, S. Simpson, J. Nitz, G. A. Rojas, E. Zurek, L. Routaboul, B. Doudin, P. Braunstein, P. A. Dowben and A. Enders, Chem. Commun., 2012, 48, 7143-7145; (b) S. Simpson, D. A. Kunkel, J. Hooper, J. Nitz, P. A. Dowben, L. Routaboul, P. Braunstein, B. Doudin, A. Enders and E. Zurek, J. Phys. Chem. C, 2013, 117, 16406-16415; (c) D. A. Kunkel, J. Hooper, S. Simpson, D. P. Miller, L. Routaboul, P. Braunstein, B. Doudin, S. Beniwal, P. A. Dowben, R. Skomski, E. Zurek and A. Enders, J. Chem. Phys., 2015, 142, 101921.

13 Y. Fang, P. Nguyen, O. Ivasenko, M. P. Aviles, E. Kebede, M. S. Askari, X. Ottenwaelder, U. Ziener, O. Siri and L. A. Cuccia, Chem. Commun., 2011, 47, 11255-11257. 
14 (a) P. Gao and M. J. Weaver, J. Phys. Chem., 1985, 89, 5040-5046; (b) D. Syomin, J. Kim, B. E. Koel and G. B. Ellison, J. Phys. Chem. B, 2001, 105, 8387-8394; (c) W.-K. Chen, M.-J. Cao, S.-H. Liu, C.-H. Lu, Y. Xu and J.-Q. Li, Chem. Phys. Lett., 2006, 417, 414-418; (d) C. Schuster and U. Schwingenschloegl, Chem. Phys. Lett., 2009, 468, 75-78; (e) A. J. Britton, A. Rienzo, J. N. O'Shea and K. Schulte, J. Chem. Phys., 2010, 133, 094705; $(f)$ J. Wellendorff, A. Kelkkanen, J. J. Mortensen, B. I. Lundqvist and T. Bligaard, Top. Catal., 2010, 53, 378-383; (g) A. Batra, G. Kladnik, H. Vazquez, J. S. Meisner, L. Floreano, C. Nuckolls, D. Cvetko, A. Morgante and L. Venkataraman, Nat. Commun., 2012, 3, 2083; (h) W. Liu, J. Carrasco, B. Santra, A. Michaelides, M. Scheffler and A. Tkatschenko, Phys. Rev. B: Condens. Matter Mater. Phys., 2012, 86, 245405; ( $i$ ) T. S. Chwee and M. B. Sullivan, J. Chem. Phys., 2012, 137, 134703; $(j)$ H. Yildirim, T. Greber and A. Kara, J. Phys. Chem. C, 2013, 117, 20572-20583.

15 For some recent reviews see for examples: (a) V. Bukhariya, A. Shukla, J. Mehta and R. Charde, Int. J. Pharm. Chem., 2011, 1, 21-38; (b) S. Chandak, D. Sharma, V. Sharma and A. Dubey, Int. J. Pharm. Sci. Rev. Res., 2012, 15, 15-22; (c) R. B. N. Baig and R. S. Varma, Chem. Soc. Rev., 2012, 41, 1559-1584; (d) M. B. Gawande, V. D. B. Bonifacio, R. Luque, P. S. Branco and R. S. Varma, Chem. Soc. Rev., 2013, 42, 5522-5551; (e) A. Majumder, R. Gupta and A. Jain, Green Chem. Lett. Rev., 2013, 6, 151-182; $(f)$ D. Garella, E. Borretto, A. Di Stilo, K. Martina, G. Cravotto and P. Cintas, Med. Chem. Commun., 2013, 4, 1323-1343; (g) A. K. Gupta, N. Singh and K. N. Singh, Curr. Org. Chem., 2013, 17, 474-490; (h) F. Messina and O. Rosati, Curr. Org. Chem., 2013, 17, 1158-1178.

16 (a) Z. Dahmani, M. Rahmouni, R. Brugidou, J. P. Bazureau and J. Hamelin, Tetrahedron Lett., 1998, 39, 8453-8456; (b) G. Rashinkar, S. Kamble, A. Kumbhar and R. Salunkhe, Transition Met. Chem., 2010, 35, 185-190; (c) M. Lefever, J. W. Kosmeder II, M. Farrell and C. Bieniarz, Bioconjugate Chem., 2010, 21, 1773-1778; (d) A. Gediz Erturk and Y. Bekdemir, Phosphorus, Sulfur Silicon Relat. Elem., 2014, 189, 285-292.

17 P. Braunstein, D. Bubrin and B. Sarkar, Inorg. Chem., 2009, 48, 2534-2540.

18 (a) T. A. Darwish, Y. Tong, M. James, T. L. Hanley, Q. Peng and S. Ye, Langmuir, 2012, 28, 13852-13860; (b) F. M. Hoffmann, Y. S. Hoo, T. H. Cai, M. G. White and J. Hrbek, Surf. Sci., 2012, 606, 1906-1913; (c) M. Mucha, E. Kaletova, A. Kohutova, F. Scholz, E. S. Stensrud, I. Stibor, L. Pospisil, F. von Wrochem and J. Michl, J. Am. Chem. Soc., 2013, 135, 5669-5677; (d) T. Shimoaka, K. Rikiyama, Y. Katsumoto and
T. Hasegawa, Anal. Bioanal. Chem., 2013, 405, 9411-9418; (e) K. Csanko, G. Kozma, L. Valkai, A. Kukovecz, Z. Konya, P. Sipos and I. Palinko, J. Mol. Struct., 2013, 1044, 32-38; (f) S. Kanata, T. Nishino, R. Makiura, S. Saiki and N. Hayashi, Anal. Sci., 2013, 29, 405-409; (g) M. Bouriga, M. M. Chehimi, C. Combellas, P. Decorse, F. Kanoufi, A. Deronzier and J. Pinson, Chem. Mater., 2013, 25, 90-97; (h) O. Buriez, F. I. Podvorica, A. Galtayries, E. Labbe, S. Top, A. Vessieres, G. Jaouen, C. Combellas and C. Amatore, J. Electroanal. Chem., 2013, 699, 21-27; (i) H. Jacob, K. Kathirvel, F. Petersen, T. Strunskus, A. Bannwarth, S. Meyer and F. Tuczek, Langmuir, 2013, 29, 8534-8543; (j) H.-X. Zhang, Y. Sasaki, M. Abe, Y. Zhang, S. Ye, M. Osawa and K. Uosaki, J. Electroanal. Chem., 2014, 714-715, 51-55; (k) W. Azzam, N. A. F. Al-Rawashdeh, N. Al-Refaie, O. Shekhah and A. Bashir, J. Phys. Chem. C, 2014, 118, 4846-4859; (l) S. Gam Derouich, C. Rinfray, G. Izzet, J. Pinson, J.-J. Gallet, F. Kanoufi, A. Proust and C. Combellas, Langmuir, 2014, 30, 2287-2296; (m) H. Jacob, S. Ulrich, U. Jung, S. Lemke, T. Rusch, C. Schuett, F. Petersen, T. Strunskus, O. Magnussen, R. Herges and F. Tuczek, Phys. Chem. Chem. Phys., 2014, 16, 22643-22650; (n) S. J. Jethwa, F. Grillo, H. A. Fruchtl, G. J. Simpson, M.-J. Treanor, R. Schaub, S. M. Francis, N. V. Richardson and R. A. Aitken, Chem. Commun., 2014, 50, 10140-10143.

19 Kappa CCD Operation Manual, Nonius BV, Delft, The Netherlands, 1997; G. M. Sheldrick, SHELXL97, Program for the Refinement of Crystal Structures, University of Gottingen, Germany, 1997.

20 M. J. Frisch, G. W. Trucks, H. B. Schlegel, G. E. Scuseria, M. A. Robb, J. R. Cheeseman, G. Scalmani, V. Barone, B. Mennucci, G. A. Petersson, H. Nakatsuji, M. Caricato, X. Li, H. P. Hratchian, A. F. Izmaylov, J. Bloino, G. Zheng, J. L. Sonnenberg, M. Hada, M. Ehara, K. Toyota, R. Fukuda, J. Hasegawa, M. Ishida, T. Nakajima, Y. Honda, O. Kitao, H. Nakai, T. Vreven Jr, J. A. Montgomery, J. E. Peralta, F. Ogliaro, M. J. Bearpark, J. Heyd, E. N. Brothers, K. N. Kudin, V. N. Staroverov, R. Kobayashi, J. Normand, K. Raghavachari, A. P. Rendell, J. C. Burant, S. S. Iyengar, J. Tomasi, M. Cossi, N. Rega, N. J. Millam, M. Klene, J. E. Knox, J. B. Cross, V. Bakken, C. Adamo, J. Jaramillo, R. Gomperts, R. E. Stratmann, O. Yazyev, A. J. Austin, R. Cammi, C. Pomelli, J. W. Ochterski, R. L. Martin, K. Morokuma, V. G. Zakrzewski, G. A. Voth, P. Salvador, J. J. Dannenberg, S. Dapprich, A. D. Daniels, Ö. Farkas, J. B. Foresman, J. V. Ortiz, J. Cioslowski and D. J. Fox, Gaussian, Inc., Wallingford, CT, USA, 2009.

21 A. D. Becke, Phys. Rev. E: Stat., Nonlinear, Soft Matter Phys., 1988, 38, 3098. 